OPEN ACCESS

Edited by:

Zhulong Chan,

Huazhong Agricultural University,

China

Reviewed by:

Man Zhou,

University of Minnesota, United States

Sun Xinbo,

Agricultural University of Hebei, China

*Correspondence:

Kehua Wang

kehwang@cau.edu.cn

Wanjun Zhang

wjzhang@cau.edu.cn

tThese authors have contributed equally to this work.

Specialty section:

This article was submitted to

Plant Abiotic Stress,

a section of the journal

Frontiers in Plant Science

Received: 03 March 2017 Accepted: 29 May 2017

Published: 21 June 2017

Citation:

Wang K, Liu Y, Tian J, Huang K, Shi T, Dai $X$ and Zhang W (2017)

Transcriptional Profiling and Identification of Heat-Responsive Genes in Perennial Ryegrass by RNA-Sequencing.

Front. Plant Sci. 8:1032. do: 10.3389/fpls.2017.01032

\section{Transcriptional Profiling and Identification of Heat-Responsive Genes in Perennial Ryegrass by RNA-Sequencing}

\author{
Kehua Wang ${ }^{1 *}$, Yanrong Liu ${ }^{1 \dagger}$, Jinli Tian ${ }^{1}$, Kunyong Huang ${ }^{1}$, Tianran Shi ${ }^{1}$, Xiaoxia Dai $^{1}$ \\ and Wanjun Zhang ${ }^{1,2 *}$
}

${ }^{1}$ Department of Grassland Science, China Agricultural University, Beijing, China, ${ }^{2}$ National Energy R\&D Center for Biomass, China Agricultural University, Beijing, China

Perennial ryegrass (Lolium perenne) is one of the most widely used forage and turf grasses in the world due to its desirable agronomic qualities. However, as a cool-season perennial grass species, high temperature is a major factor limiting its performance in warmer and transition regions. In this study, a de novo transcriptome was generated using a cDNA library constructed from perennial ryegrass leaves subjected to shortterm heat stress treatment. Then the expression profiling and identification of perennial ryegrass heat response genes by digital gene expression analyses was performed. The goal of this work was to produce expression profiles of high temperature stress responsive genes in perennial ryegrass leaves and further identify the potentially important candidate genes with altered levels of transcript, such as those genes involved in transcriptional regulation, antioxidant responses, plant hormones and signal transduction, and cellular metabolism. The de novo assembly of perennial ryegrass transcriptome in this study obtained more total and annotated unigenes compared to previously published ones. Many DEGs identified were genes that are known to respond to heat stress in plants, including HSFs, HSPs, and antioxidant related genes. In the meanwhile, we also identified four gene candidates mainly involved in $\mathrm{C}_{4}$ carbon fixation, and one TOR gene. Their exact roles in plant heat stress response need to dissect further. This study would be important by providing the gene resources for improving heat stress tolerance in both perennial ryegrass and other cool-season perennial grass plants.

Keywords: transcriptional profiling, heat-responsive genes, HSPs, perennial ryegrass

\section{INTRODUCTION}

High temperature is a common abiotic stress for higher plants. It is estimated that the annual mean air temperature of about $23 \%$ of land on the earth is above $40^{\circ} \mathrm{C}$ (Leone et al., 2003). It could be getting worse due to current trends in global warming. It is anticipated the global temperature will increase another $1.7-3.8^{\circ} \mathrm{C}$ by 2100 (Wigley and Raper, 1992; IPCC, 2014). Temperature above the optimum for healthy plant growth is known as heat stress. Heat is understood as the upper temperature range in which active plant life is stressed, but is still possible (normally $10-15^{\circ} \mathrm{C}$ 
above the optimum temperature) (Schulze et al., 2005). Higher temperature affects the balance of growth and development by accelerating and redirecting metabolic processes. Under heat stress, plants respond at all levels, from morphological adaptations to physiological changes to molecular regulations. A number of important adaptive changes occur in terms of carbon and nitrogen metabolism, antioxidant responses, hormone homeostasis, and expression of many specific stress response genes/proteins (e.g., HSPs) (Schulze et al., 2005; Wahid et al., 2007).

Perennial ryegrass is native to Europe, Asia, and northern Africa, and becomes one of the most widely used forage and turf grasses worldwide. It has many desirable agronomic qualities, such as rapid establishment, long growing season, and high yield under favorable environments and conditions. However, as a cool-season perennial grasses, it grows best at the temperature range between 16 and $24^{\circ} \mathrm{C}$, and the growth normally starts to decline when temperature exceeds $27^{\circ} \mathrm{C}$. It does not withstand hot weather, and high temperature is a major factor limiting its performance in warmer and transition regions (Turgeon, 2011). Some studies of perennial ryegrass under heat stress have been conducted, but they are typically focused on breeding new cultivars, growth, or the physiological and biochemical aspects of the plants' response (Minner et al., 1983; Sugita, 1991; Jiang and Huang, 2001; Kauffman et al., 2007; Zhang et al., 2013; Barnes et al., 2014; Chen et al., 2016; Wang and Xiong, 2016). To date, data regarding the molecular mechanism of perennial ryegrass responding to heat stress is very limited.

Transcriptomic studies have been widely adopted to systematically investigate the genes either involved in certain bioprocess and development stage or responses to different abiotic and biotic changes, particularly with the development of high-throughput next generation sequencing (NGS) (Wang et al., 2009; Hyun et al., 2012; Gao et al., 2013; Nejat et al., 2015). A wide spectrums of heat response genes have been identified in different plant species using transcriptomic methods, including Arabidopsis (Rizhsky et al., 2002; Larkindale and Vierling, 2008; Song et al., 2016), rice (Oryza sativa) (Sarkar et al., 2014; Wu et al., 2015), maize (Zea mays) (Dutra et al., 2015; Frey et al., 2015; Casaretto et al., 2016), tomato (Solanum lycopersicum) (Bita et al., 2011; Cheng et al., 2012), potato (Solanum tuberosum) (Ginzberg et al., 2009; Tang et al., 2016), carnation (Dianthus caryophyllus) (Wan et al., 2015), wheat (Triticum aestivum) (Qin et al., 2008), and Brachypodium distachyon (Chen and Li, 2017). However, little information is available regarding heat responsive genes at global transcriptome level in the perennial cool-season grasses, especially perennial ryegrass. Only very recently, Wang Y. et al. (2016) analyzed perennial ryegrass under temperature stress by RNA-Seq, and they mainly focused on heat shock factor (HSF) genes. There are many more other genes are important for plants in response to heat stress, such as heat shock proteins (HSPs), reactive oxygen species (ROS) scavenger genes, signal transduction and other transcription factors (TFs) (Schulze et al., 2005; Kotak et al., 2007; Wahid et al., 2007; Hasanuzzaman et al., 2013).

In this study, we generated a de novo transcriptome using a leaf cDNA library of perennial ryegrass subjected to short-term heat stress. Then the expression profiling and identification of perennial ryegrass heat response genes by digital gene expression (DGE) analyses was performed using this transcriptome as the reference set of sequences. The objectives of this study were to identify gene candidates with changed transcript levels in perennial ryegrass leaves under heat stress, particularly, those genes potentially involved in transcriptional regulation, antioxidant responses, plant hormones and signal transduction, and cellular metabolism. This study would be important by providing the gene resources for improving heat stress tolerance in both perennial ryegrass and other cool-season perennial grass plants.

\section{MATERIALS AND METHODS}

\section{Plant Materials and Heat Stress Treatment}

Perennial ryegrass 'Citation Fore' (PureSeed, Canby, OR, United States) was used in this study. Grass plants were grown in a greenhouse at China Agricultural University (Beijing, China) at $25 \pm 3 / 18 \pm 2{ }^{\circ} \mathrm{C}$ (day/night) for $14 \mathrm{~h}$ (day) and $10 \mathrm{~h}$ (night) before moving into growth chambers for high temperature treatments. Plants were clonally propagated from tillers and grown in plastic pots $(12.0 \mathrm{~cm} \times 10.5 \mathrm{~cm})$ using a soil mixture of silica sand and peat $(1: 1, \mathrm{v} / \mathrm{v})$. Plants were cut weekly to maintain uniform above-ground growth, watered as needed to avoid water stress, and fertilized weekly with Miracle-Gro TEP6 (24-12-14, $\mathrm{N}-\mathrm{P}-\mathrm{K}$; Scotts, Wuhan, China) at $5 \mathrm{~kg} \mathrm{~N} \mathrm{ha}^{-1}$.

Four months after been propagated from a single tiller, grasses were moved to a growth chamber for a 1-week adaptation. The growth chamber was set as the following: relative humidity $70 \% / 85 \%$ (day/night), $22 / 16^{\circ} \mathrm{C}$, and a 14 -h photoperiod with $400 \mu \mathrm{mol} \mathrm{s}{ }^{-1} \mathrm{~m}^{-2}$ PAR (photosynthetically active radiation). A week later, half of the adapted grasses were switched into another growth chamber (same model) for a short-term high temperature treatment $\left(6 \mathrm{~h}, 35 / 35^{\circ} \mathrm{C}\right)$. Leaf tissues were harvested, immediately frozen with liquid nitrogen, and then stored at $-80^{\circ} \mathrm{C}$ until analysis.

\section{RNA Isolation and Illumina Sequencing}

Total RNA was isolated from the perennial ryegrass leaf samples with Trizol reagent (Invitrogen, Carlsbad, CA, United States). The purity and integrity of the RNA were evaluated using the Implen Nano-Photometer ${ }^{\circledR}$ N50 (München, Germany) and Agilent 2100 Bioanalyzer (United States), respectively. The concentration of the RNA was determined using Qubit ${ }^{\circledR} 2.0$ Fluorometer. A total of $1.5 \mu \mathrm{g}$ RNA each sample was used for the RNA-seq analysis. NEBNext ${ }^{\circledR}$ Ultra $^{\text {TM }}$ RNA Library Prep Kit for Illumina ${ }^{\circledR}$ (NEB, United States) was used to generate the sequencing libraries. The cDNA (150 300 bp) were purified selectively from the libraries using AMPure XP system (Beckman Coulter, Beverly, MA, United States). PCR Enriched cDNAs were used to create the final cDNA library, and then sequenced with Illumina $\mathrm{HiSeq}^{\mathrm{TM}} 2500$ platform, using paired-end reads $(2 \times 100$ nucleotides $)$. The sequencing was carried out at Novogene Corporation (Beijing, China). 


\section{Real-Time Quantitative PCR Analysis for RNA-Seq Data Validation}

Real-time quantitative PCR of 16 different genes using 7500 Real-Time PCR System (Applied Biosystems) was carried out to validate the RNA-seq results. Primer sequences for qRT-PCR were designed using Primer premier 6 software and were listed in Supplementary Table S1. Gene expression levels were calculated by the $2^{-\Delta \Delta C t}$ method (Livak and Schmittgen, 2001). Each plate was repeated three times in independent runs for all reference and selected genes.

\section{Data Analysis Quality Control}

Clean reads/data were obtained from raw data after removing the reads containing adapter or ploy- $\mathrm{N}$ and other low-quality reads. In the meanwhile, the clean data Q20, Q30 value, GCcontents, and the level of sequence duplication were calculated (Supplementary Table S2).

\section{Sequence Assembly and Gene Functional Annotation}

Since there is no publicly available genome of perennial ryegrass (Pfeifer et al., 2013), Trinity was used to construct and accomplish the de novo assembly of the transcriptome here (Grabherr et al., 2011). Unigenes were blasted using blastx against databases publicly available, including $\mathrm{Nr}$ (NCBI non-redundant protein database ${ }^{1}$ ), Nt (NCBI non-redundant nucleotide sequences ${ }^{1}$ ), Pfam (Protein family), Swiss-Prot ${ }^{2}$, KEGG (the Kyoto Encyclopedia of Genes and Genomes pathway database ${ }^{3}$ ), KOG/COG (Cluster of Orthologous Groups database $^{4}$ ), and GO (Gene Ontology), and the best aligning results were used to decide the direction of the sequence and CDS (coding sequence) of unigenes. A typical cutoff value of $E<10^{-5}$ was used. ESTScan (Iseli et al., 1999) was used to predict a unigene's coding regions as well as to decide its sequence direction when it was found not to be aligned to any of the databases above.

\section{Differential Expression Analysis}

RSEM (Li and Dewey, 2011) was used to calculate gene expression levels. To further reveal the heat stress responsive genes, we performed comparative transcriptomic analysis among the pools of control and high temperature RNA samples. The genes with a $p_{\text {adj }}(P$-value-adjusted $)<0.05$ were identified as differentially expressed (down- or upregulated) genes (DEGs) according to (Anders and Huber, 2010). All the DEGs were further annotated by GO and KEGG pathway enrichment analyses. GO enrichment analysis of the DEGs was implemented by the GOseq $\mathrm{R}$ packages based Wallenius non-central hyper-geometric distribution (Young et al., 2010). The KOBAS software was performed to test the statistical enrichment of differential expression genes

\footnotetext{
${ }^{1}$ www.ncbi.nlm.nih.gov

${ }^{2}$ www.expasy.ch/sprot

${ }^{3}$ www.genome.jp/kegg

${ }^{4}$ www.ncbi.nlm.nih.gov/COG
}

in KEGG pathways (Mao et al., 2005; Kanehisa et al., 2008).

\section{RESULTS}

\section{Illumina Paired-End Sequencing and Assembly}

Here the library was sequenced according to Illumina pairedend protocol. After removing adaptors and low-quality reads, $62,723,918$ clean paired-end reads ( $94.57 \%$ of the raw reads data) were obtained. And the average sample GC-rich content and the Q20 level was 55.53 and 95.21\%, respectively. De novo assembly of the clean reads data with Trinity identified 290,039 contigs. The N50 gene size, average contig length, and the maximum contig length was 1920,1023 , and $16,826 \mathrm{bp}$, respectively. A total of 185,671 unigenes were obtained, and the longest length transcript for each unigene was selected for further analysis. The average length of unigenes was $675 \mathrm{bp}$, and transcripts with lengths of equal or greater than $500 \mathrm{bp}$ accounted for about $51.5 \%$ of all transcripts (Table 1). The accession number of the transcriptome data deposited to Sequence Read Archive (SRA) is SUB2445006.

\section{Annotation and Functional Classification}

All assembled unigenes were submitted to a Blastx search against the public protein databases in order to validate and annotate the assembled unigenes. Among the total 185,671 unigenes, 96,106 (51.76\%), 78,959 (42.52\%), and 74,188 (39.95\%) unigenes showed homology with the sequences in the databases of $\mathrm{Nt}, \mathrm{Nr}$, and SwissProt, respectively. And 121,271 unigenes were annotated in at least one database searched against (Supplementary Table S3).

The unigene sequences were further characterized by the assignment of GO terms (Figure 1 and Supplementary Table S4). In total, 1,961 functional GO terms were assigned among 60,117 unigenes with BLAST matching to known proteins. The most highly represented GO categories of biological processes were cellular processes (32,219 unigenes), metabolic processes $(30,197$ unigenes), and biological regulation (10,784 unigenes), which

TABLE 1 | Summary of sequencing and de novo assembly.

\begin{tabular}{ll}
\hline Item & Values \\
\hline Clean reads & $62,723,918$ \\
Clean bases (nt) & $10,100,331,424$ \\
GC-content (\%) & 55.53 \\
Q20 percentage (\%) & 95.21 \\
Total assemble size (nt) & $296,742,727$ \\
Number of contigs & 290,039 \\
Average length of contig (nt) & 1,023 \\
Shortest length of contig (nt) & 201 \\
Longest length of contig (nt) & 16,826 \\
N50 & 1,920 \\
Total number of unigenes & 185,671 \\
Length of all unigenes (nt) & $125,318,772$ \\
Average sequence size of unigenes (nt) & 675 \\
N50 & 1,169
\end{tabular}




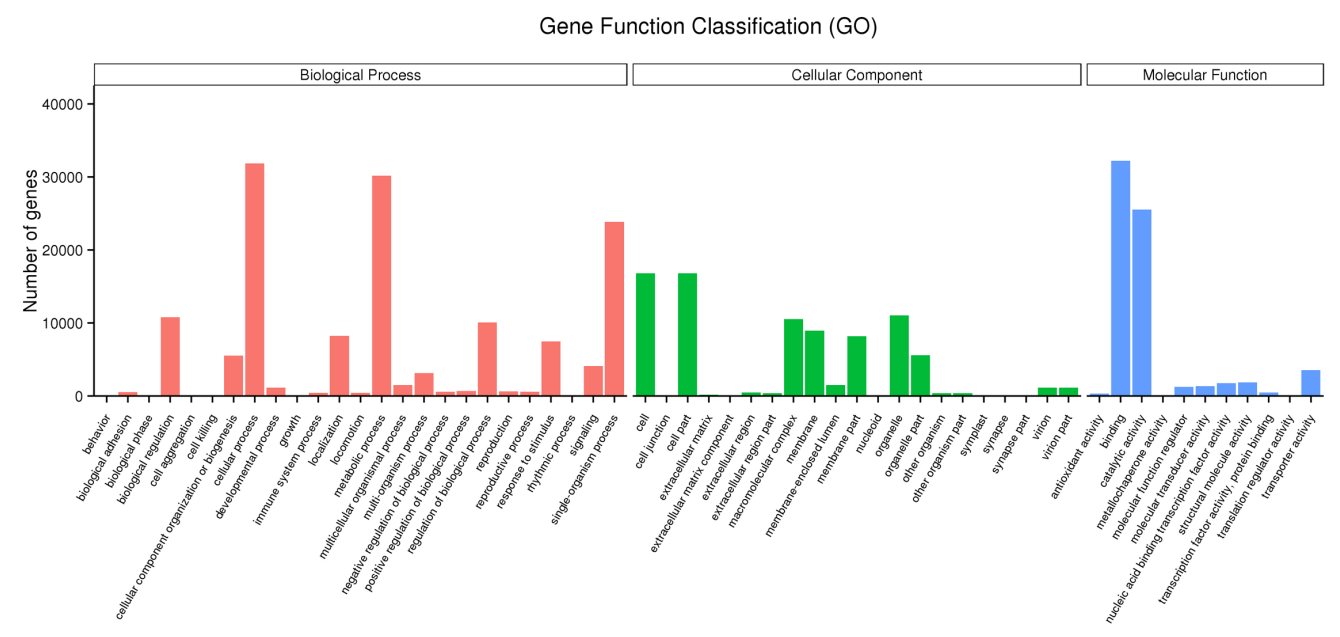

FIGURE 1 | Gene ontology (GO) annotations of non-redundant consensus sequences of perennial ryegrass. Best hits were aligned to the GO database, and most consensus sequences were grouped into three major functional categories namely, biological process (BP), cellular component (CC), and molecular function (MF).

suggested a high degree of basic metabolic activity and biological regulation in the heat stressed tissues. Similarly, for the categories of cellular component, cell $(16,786)$ and cell part $(16,783)$ were the two mostly represented. Under the classification of molecular functions, the binding (32,219 unigenes) and catalytic activities $(25,533)$ represented the two largest categories. Those GO categories of TFs (484 unigenes), signal transduction $(4,112$ unigenes), response to stimulus (7,467 unigenes), and antioxidant activity (318 unigenes) were important in general stress response, but with less assigned unigenes.

All unigenes were further aligned to the eukaryotic Ortholog Groups (KOG) database to predict and classify their possible functions. A total of 31,021 sequences were assigned to KOG classification of 26 categories, respectively. Based on the KOG classification, the unigenes were then analyzed using the KEGG pathway database. Out of the 185,671 unigenes identified in the study, 29,124 (15.69\%) were assigned to132 KEGG pathways belonging to five main categories (Figure 2 and Supplementary Table S5). Among the 132 KEGG pathways, 10 most assigned ones were carbohydrate metabolism (10.6\%), translation (10\%), overview $(8.1 \%)$, folding, sorting and degradation $(8 \%)$, amino acid metabolism (6.9\%), energy metabolism (5.3\%), transport and catabolism (5.2\%), lipid metabolism (5.2\%), transcription (4.1\%), and environmental adaptation (3.8\%). These results indicated that both active metabolic processes and environmental adaptation responses were occurring in perennial ryegrass.

\section{Differential Gene Expression of Perennial Ryegrass in Response to Heat Stress}

To reveal the molecular events and identify genes with altered expression levels under heat stress, the DGE libraries were constructed using RNA from the pools of control and the heat stressed plant RNA samples and sequenced. Using the criteria of twofold up- or down-regulation [ $\log _{2} \mathrm{FC}$ (fold change) $\leqq 1$ or $\geqq-1$ ], 11,275 genes were identified as differentially-regulated genes (DEGs), including 4756 (42.2\%) up-regulated and 6519
(57.8\%) down-regulated unigenes (Figure 3). Strongly up-related genes $\left(\log _{2} \mathrm{FC} \leqq 4\right)$ (3052) and down-related genes ( $\log _{2} \mathrm{FC}$ $\geqq-4$ ) (1132) under heat stress were further identified from expression profile analysis (Supplementary Table S6). These genes mostly comprised stress response genes, including HSPs, signal transduction factors, and TFs. Fifty-two HSP genes whose expressions were present under heat stress, but not in control. Interestingly, there were 99 highly induced genes (256-fold or higher) by heat stress whose functions were not known.

\section{Gene Ontology Analysis of the Functional Annotation and Classification of the DEGs}

Gene Ontology classification of the significantly regulated genes was carried out to identify the heat stress response related functional processes in perennial ryegrass leaves. Among the total 251 identified sub-classifications of GO functions, the predominant $60 \mathrm{GO}$ classifications were shown in Figure 4. Other than the commonly enriched GO classifications, such as metabolic process, cellular process, catalytic activity, both response to abiotic stimulus (GO:0009628) and antioxidant activity (GO:0016209) were among the predominantly enriched groups. In addition, regulated genes mainly related to temperature stress responses are also enriched, such as response to heat (GO:0009408), HSP binding (GO:0031072), and response to temperature stimulus (GO:0009266).

\section{KEGG Pathway Analysis of the Heat Responsive Genes}

To further determine whether the heat responsive genes were involved in specific pathways, the DEGs were used as objects to search against the KEGG pathway database. The top 20 obviously enriched pathways are shown in Figure 5. The 'plantpathogen interaction' pathway enriched the most DEGs, but 'photosynthesis - antenna proteins,' 'photosynthesis,' and 'carbon 


\section{KEGG Classification}

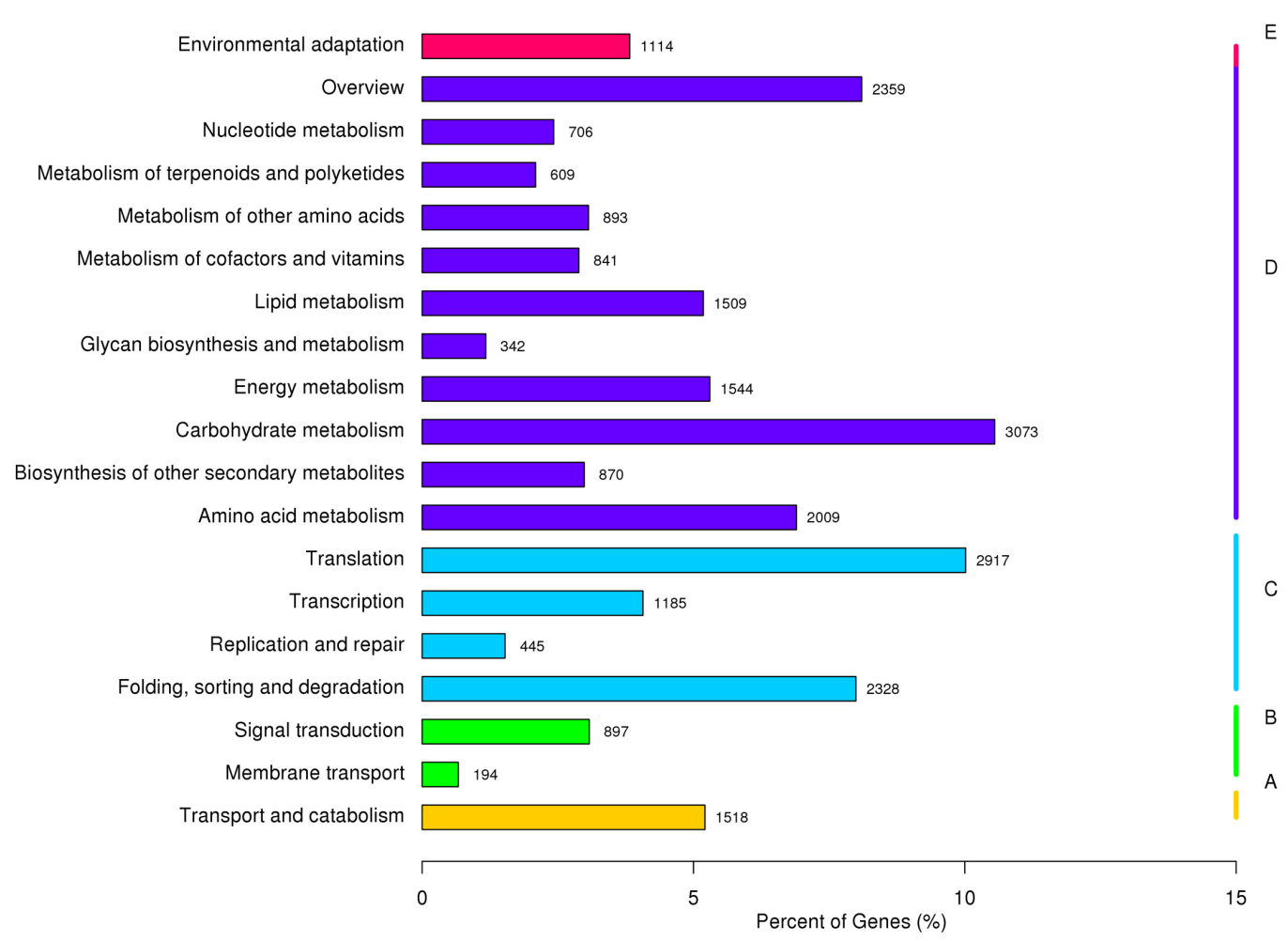

FIGURE 2 | Pathway assignment of perennial ryegrass genes based on the Kyoto Encyclopedia of Genes and Genomes (KEGG) database. (A) Classification based on cellular process categories, (B) classification based on environmental information processing categories, (C) classification based on genetic information processing categories, (D) classification based on metabolism categories, and (E) classification based on organismal systems categories.

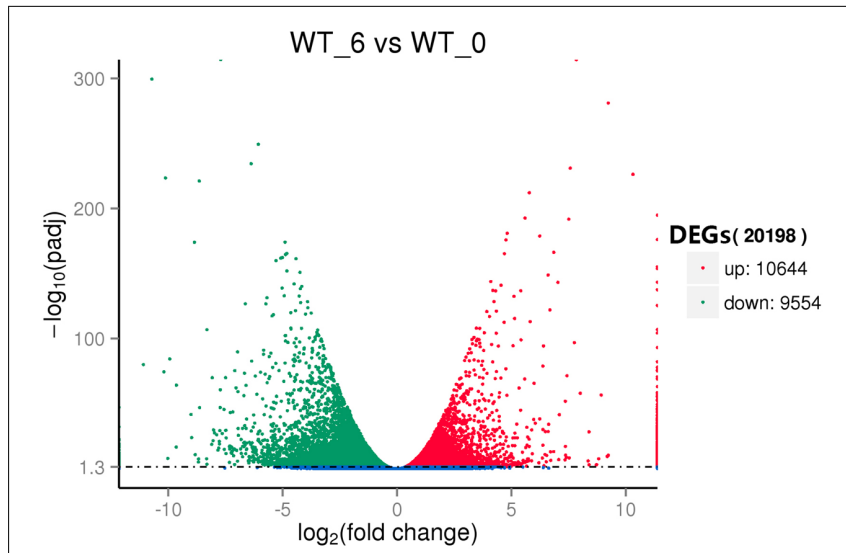

FIGURE 3 | Volcano plot of the differentially expressed genes (DEGs) between the control (WT_0) and heat stressed (WT_6) perennial ryegrass.

fixation in photosynthetic organisms' were the most significantly enriched according to the adjusted $P$-values (Figures 5, 6). For instance, in 'photosynthesis' group, three photosystem II genes, PsbD (photosystem II P680 reaction center D2 protein), PsbQ (photosystem II oxygen-evolving enhancer protein 3), and PsbR (photosystem II $10 \mathrm{kDa}$ protein) were up-regulated, while two other photosystem II genes (Psb27, photosystem II Psb27 protein; Psb28, photosystem II $13 \mathrm{kDa}$ protein) and PetJ (cytochrome c6) in photosynthetic electron transport were downregulated. In 'photosynthesis - antenna proteins' group, Lbcal (light-harvesting complex I chlorophyll a/b binding protein 1) and Lbcb4 (light-harvesting complex II chlorophyll a/b binding protein 4) were stimulated. For 'carbon fixation' group, aspartate aminotransferase (AST), cytoplasmic and phosphoenolpyruvate carboxykinase (ATP) (PEPCK) were up-regulated, while pyruvate orthophosphate dikinase (PPDK) and malate dehydrogenase (decarboxylating) (NAD-ME) were down-regulated. Several other less enriched but important pathways for heat responses included plant hormone signal transduction, zeatin biosynthesis, and peroxisome (Supplementary Table S7 and Figure S1). Interestingly, mTOR signaling pathway, a signaling network mostly known for its role in a number of human pathological conditions (Hall, 2008), was identified by KEGG analysis as well (Supplementary Figure S2).

\section{HSPs in Response to Heat Stress}

Out of the list of significantly regulated genes, 63 HSPs were largely up-regulated $\left(\log _{2} \mathrm{FC} \geqq 4\right)$ and 1 HSP was highly down-regulated $\left(\log _{2} \mathrm{FC} \leqq-4\right)$. Of these highly up-regulated 


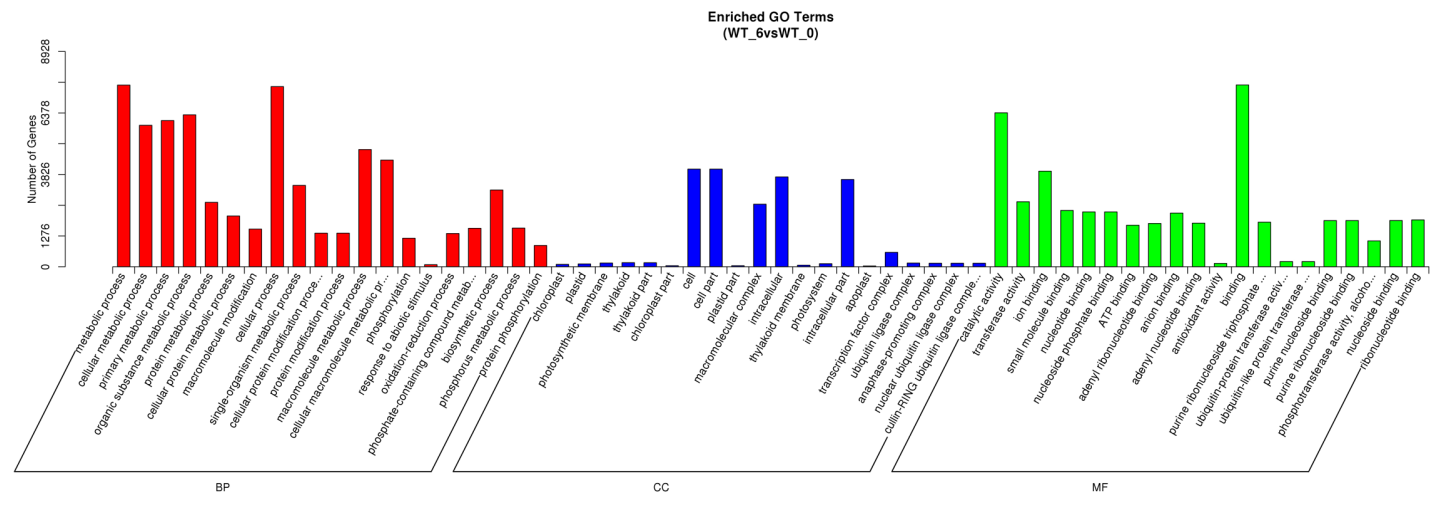

FIGURE 4 | Gene ontology classifications of DEGs between the control and heat stressed perennial ryegrass. The $Y$-axis represents the number of DEGs in a category. The results of heat stressed (WT_6) vs. control (WT_0) are summarized in three main categories: BP, CC, and MF.

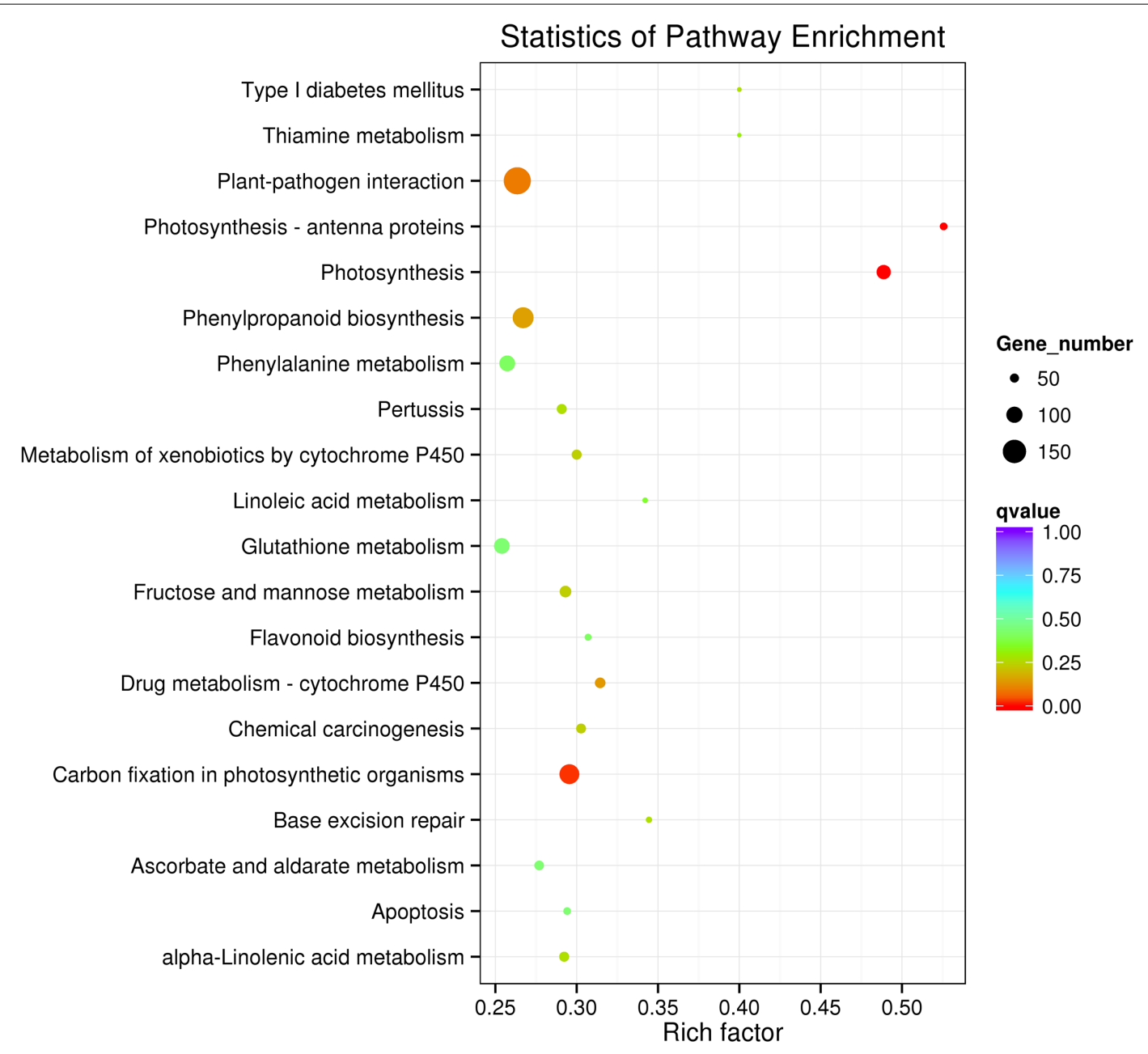

FIGURE 5 | Kyoto Encyclopedia of Genes and Genomes enrichments of the annotated DEGs between the control and heat stressed perennial ryegrass. The left $Y$-axis indicates the KEGG pathway. The $X$-axis indicates the Rich factor. A high $q$-value is represented by blue, and a low $q$-value is represented by red.

HSP genes, 18 genes were various types of small HSP (sHSP) (cytosolic classes I, II, and III, chloroplast, mitochondrial and endoplasmic reticulum), 6 coded for HSP60, 16 for
HSP70, 15 for HSP90, and 8 for HSP101. The highly downregulated HSP belonged to HSP70 family (Supplementary Tables S6, S8). 


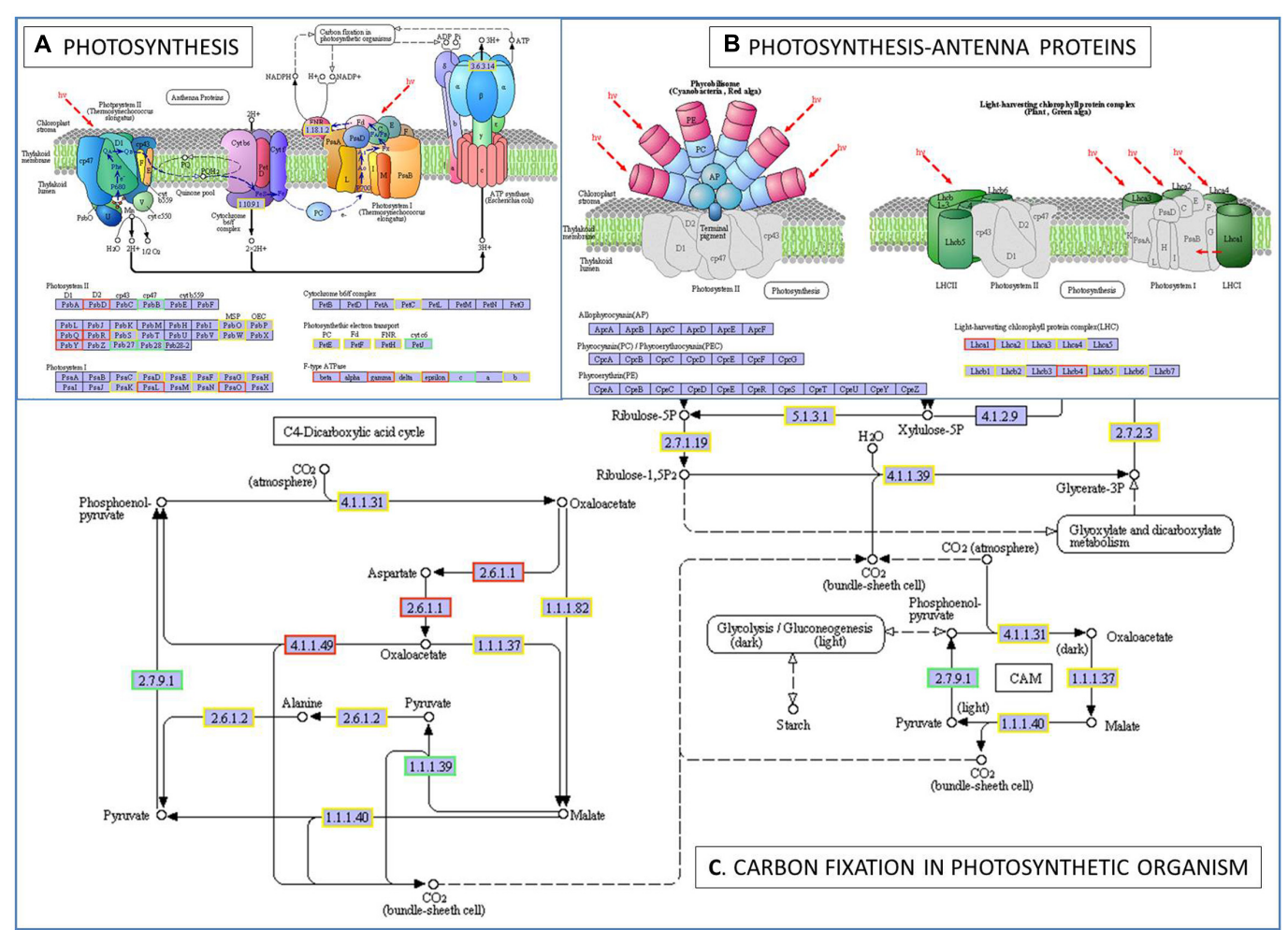

FIGURE 6 | The pathways of photosynthesis (A), photosynthesis-antenna proteins (B), and carbon fixation in photosynthetic organism (C) enriched by KEGG analysis. A gene/protein name in a red and blue box represent up-regulation and down-regulation under heat stress, respectively. PsbD, photosystem II P680 reaction center D2 protein (EC:1.10.3.9); PsbB, photosystem II CP47 chlorophyll apoprotein; PsbQ, photosystem II oxygen-evolving enhancer protein 3; PsbR, photosystem II 10 kDa protein; Psb27, photosystem II Psb27 protein; Psb28, photosystem II 13 kDa protein; PsaL, photosystem I subunit XI; PsaO, photosystem I subunit; petJ, cytochrome c6; Lhca1, light-harvesting complex I chlorophyll a/b binding protein 1; Lhcb4, light-harvesting complex II chlorophyll a/b binding protein 4; EC:2.6.1.1, aspartate aminotransferase, cytoplasmic; EC:4.1.1.49, phosphoenolpyruvate carboxykinase (ATP); EC:2.7.9.1, pyruvate, orthophosphate dikinase; EC:1.1.1.39, malate dehydrogenase (decarboxylating).

\section{Transcription Factors in Response to Heat Stress}

Transcription factors of different families were significantly regulated in response to heat stress. HSF, AP2/EREBP, MYB, bHLH, and DIVARICATA families were among the strongly up- or down-regulated TFs $\left(\log _{2} \mathrm{FC} \geqq 2 / \leqq-2\right)$. In addition, one gene from HSF (c37944_g1, Hsf24-like), AP2/EREBP (c25197_g1, ERF003), NAC (c11267_g1, NAC029), DIVARICATA (c1152_g1, TF DIVARICATA), and MBF1 (c85706_g1, MBF1a) family was only found after heat stress. For HSFs, 10 of them were significantly up-regulated, including the one present only under heat and one increased over 21-folds (c37944_g1, Hsf24; c61648_g4, HsfA-2a). In contrast, 11 HSF genes exhibited lower expression levels compared to those under the control condition, and $H s f A-2 \mathrm{~d}$ was the mostly strongly down-regulated $\left(\log _{2} \mathrm{FC}\right.$ values of -4.0) (Supplementary Tables S6, S8).

\section{Effects of Heat Stress on Antioxidant Response Genes}

The group of antioxidant activity (GO:0016209) was enriched by GO term analysis. Over 130 genes involved in antioxidant response were either up- or down-regulated. SODA (mitochondrial Fe/Mn SOD), SODB (chloroplastic Fe/Mn SOD), and SODCP (chloroplastic $\mathrm{Cu} / \mathrm{Zn} \mathrm{SOD}$ ) were all up-regulated. Most of the 24 peroxidase $(P O D)$ genes identified (peroxidase 1 , $2,3,4,5,12,15,16,17,18,21,24,35,42,43,47,51,54,56,65$, $68,70, \mathrm{~N} 1$, and $\mathrm{P} 7)$ were down-regulated, except peroxidase 12 , 21, 42, 51, and N1 (PER12, PER21, PER42, PER51, and poxN1). In contrast, the majority of the differentially expressed ascorbate $P O D$ genes ( $A P X 1, A P X 2, A P X 3, A P X 4, A P X 6$, and APXT) were up-regulated, except for $A P X 4$ and a copy of $A P X 2$. Both of them were slightly down-regulated $\left(\log _{2} \mathrm{FC}\right.$ was about -0.5$)$. Similarly, catalase (CAT) genes were mostly up-regulated, such as $C A T 1$ and CAT2. Respiratory burst oxidase genes $(R B O H)$ were mainly down-regulated, including $R B O H B, R B O H C, R B O H E$, and $R B O H F$ (Supplementary Tables S6, S8).

\section{RT-qPCR Validation of Gene Expression Profiles}

RT-qPCR was carried out for 16 randomly selected DEGs. Histograms were produced by comparing the FPKM determined by transcriptome analysis and RT-qPCR. Expression quantities of the selected genes using RT-qPCR were consistent with 
the results obtained with RNA-Seq analysis $\left(R^{2}=0.874\right.$, $P<0.01$ ), indicating reproducibility and credible RNA-seq data (Supplementary Figures S3, S4). One exception was c63520_g2. Its expression nearly unchanged under heat stress by RT-qPCR, but increased about twofolds in RNA-Seq DEG analysis.

\section{DISCUSSION}

Transcriptome analysis of perennial ryegrass was firstly reported nearly 10 years ago employing a Serial Analysis of Gene Expression method (SAGE), which revealed 2772 transcripts (Sathish et al., 2007). Later Studer et al. (2012) acquired 9399 non-redundant contigs and singletons of perennial ryegrass from 25,744 high-quality EST reads generated by Sanger and 454 sequencing. More recently, de novo assembly of the perennial ryegrass transcriptome using the RNA-seq strategy resulted in 185,833 transcripts with an average length of $830 \mathrm{bps}$, and 50,860 transcripts $(27.38 \%)$ were functionally annotated (Farrell et al., 2014). A very recent study (Wang Y. et al., 2016) analyzed perennial ryegrass under temperature stress by RNASeq, and they generated a total of 73,125 unigenes with an average length of 723 bps. Moreover, they found a total of 20,183 DEGs, including 15,036 up-regulated and 5147 downregulated DEGs. Here our transcriptome assembly resulted in 185,671 unigenes $(29,0039$ transcripts), and 121,271 unigenes (65.32\% of all unigenes) were annotated (Table 1). In addition, total 20198 DEGs (10.9\% of all unigenes) were detected, which consisted of 10644 up-regulated and 9554 down-regulated DEGs (Figure 3). More total unigenes and annotated unigenes were detected when compared to previously published ones, which suggested that the data obtained here were comparable or larger and sufficient for further analyzing and mining genes expressing differentially in perennial ryegrass under heat stress.

In higher plants, heat stress redirects protein synthesis by decreasing the transcription and translation of normal proteins, and stimulating the synthesis of a new set of proteins: HSPs (Schulze et al., 2005). HSPs function mainly as molecular chaperones that help other proteins maintain their native conformation, thus improving protein stability under stresses (Wahid et al., 2007). Based on their approximate molecular weight, the principal HSPs are grouped into six conserved classes: HSP100/Clp, HSP90/HtpG, HSP70/DnaK, HSP60/GroEl, HSP40/DnaJ, and the small heat shock proteins (sHSPs) (Bharti and Nover, 2002; Schulze et al., 2005). The up-regulation of this gene group is well documented when cells are exposed to elevated temperatures or other stresses (Ada et al., 1987; Lee et al., 2000; Agarwal et al., 2003; Kant et al., 2008). It is therefore not surprising that the expression of many HSPs increased after exposure to heat stress in the study. And 86 of them are strongly up-regulated, including 19 sHSP, 21 HSP40, 6 HSP60, 16 HSP70, 15 HSP90, and 9 HSP101 genes (Supplementary Table S8). Low molecular weight HSPs or sHSPs are the most dominant proteins produced in higher plants subjected to heat stress (Waters et al., 1996; Sun et al., 2002). SHSPs in the study here were the most abundant HSPs regarding the read counts. For example, one annotated sHSP (chloroplast low molecular weight HSP HSP26.7b, c56087_91) increased 584 times after heat stress, from 37.4 to 21833.4 (read counts). Wang and Luthe (2003) found that several chloroplast (CP) HSP26 genes were up-regulated upon heat stress, and suggested that quantitative differences of total CP-sHSP are more critical in conferring enhanced thermo-tolerance of creeping bentgrass (Agrostis stolonifera). Li Z. et al. (2013) reported that the expression of ApHSP16.5 and ApHSP26.8 was induced much more pronounced in the OsSIZ1 transgenic plants compared to that in WT controls, and transgenic plants were more heat tolerant than WT ones. Many studies have reported that plant heat stress tolerance is positively correlated with differences in CP-sHSP levels (Downs et al., 1998; Preczewski et al., 2000; Knight and Ackerly, 2001; Li Z. et al., 2013; Wang K. et al., 2016). All the nine HSP100 genes were only present under heat stress, indicating their important role in plant thermo-tolerance. In maize (Z. mays L.) and Arabidopsis, HSP100 are thought to be causally involved in the capacity to acquire heat stress tolerance (Hong and Vierling, 2001; NietoSotelo et al., 2002). Meanwhile, three HSP40 and one HSP70 (c51623_g5) were strongly down-regulated. Wang Y. et al. (2016) and $\mathrm{Hu}$ et al. (2014) reported similar HSP changes in perennial ryegrass and/or tall fescue using transcriptome analysis, but with fewer HSP genes.

The molecular mechanism leading to HSP expression under stresses are not entirely understood, but HSFs serve as the terminal components of signal transduction mediating the expression of HSPs and other heat stress induced transcripts are widely accepted (Pockley, 2003; Kotak et al., 2007; Penfield, 2008). Plants possess multiple HSF-encoding genes, with 19 members defined in castor bean (Ricinus communis), 21 in Arabidopsis, 24 in B. distachyon and millet (Setaria italica), 25 in rice, 27 in tomato, 30 in poplar (Populus trichocarpa) and maize, 40 in cotton (Gossypium raimondii), and 56 in wheat (Guo et al., 2008; Scharf et al., 2012; Xue et al., 2014). Here we found 39 HSF unigenes, and further gene sequence comparison identified 33 members of HSFs (Supplementary Table S8). Wang Y. et al. (2016) reported 52 HSFs in perennial ryegrass and 74 HSFs in tall fescue (Festuca arundinacea) transcriptomes, which are larger than most known species, and also more than what we identified here. HsfA1a, HsfA2, and HsfB1 was found to form a regulatory network in tomato that regulates the expression of HS-responsive genes, and HsfA2 was thought to be the major HSF in thermo-tolerant cells (Mishra et al., 2002; Baniwal et al., 2004; Guo et al., 2016). Whereas, analysis of Arabidopsis HsfA1a, $H s f A 1 b$, and $H s f A 2$ knockout mutants indicates that $H s f A 1 a$ and $H s f A 1 b$ are vital in the early phase of heat shock responsive gene expression, and that $H s f A 2$ controls gene expression under longterm heat stress and recovery condition after stress (Lohmann et al., 2004; Schramm et al., 2006; Kotak et al., 2007). Here we found members of class $H s f A 2$ were highest in quantity among all of the Hsf, and most of the HsfA2 genes (HsfA2a, $b$, and $c$ ) were up-regulated under heat stress, except HsfA2d. A similar finding was reported in both tall fescue and perennial ryegrass (Wang Y. et al., 2016). However, here HsfA1 in perennial ryegrass was largely unchanged. Wang Y. et al. (2016) reported HsfA1 was weakly up-regulated or even down-regulated in 
perennial ryegrass or tall fescue. And they postulated that HsfA2 and HsfAlin tall fescue and perennial ryegrass function independently to enhance thermo-tolerance. Likewise, heat stress also resulted in a significant increase in the expressions of other $H S F$, such as HsfA3, which was consistent to results observed in other studies (Hu et al., 2014; Xue et al., 2014; Wang Y. et al., 2016).

The expression of HSFs triggers changes in expression of downstream target genes (Kotak et al., 2007). Except the major target genes, HSPs as discussed above, HSFs were also found to directly regulate several other genes in Arabidopsis including metabolic enzymes such as inositol-3-phosphate synthase2 (Ips2) and galactinol synthase 1 (GolS1) (Panikulangara et al., 2004; Nishizawa et al., 2006), and an enzyme in antioxidant response network, APX2 (ascorbate peroxidase) (Miller and Mittler, 2006; Nishizawa-Yokoi et al., 2009). After specifically investigating the expression of the three genes under heat stress, we found the expression of APXs and IPS2 increased significantly upon heat stress, but GOLS decreased under heat stress, which is consistent with a previous study on perennial ryegrass and tall fescue under heat stress (Wang Y. et al., 2016). These indicated that there might be some difference in HSF regulation between monocots (grasses) and dicots (Arabidopsis). APX is one of the major $\mathrm{H}_{2} \mathrm{O}_{2}$ reducing peroxidases and is important for antioxidant response in plants (Blokhina et al., 2003; Ishikawa and Shigeoka, 2008). The expression of the APX gene family in Arabidopsis is regulated by heat stress, which suggests a link links between heat stress response and oxidative stress (Panchuk et al., 2002; Suzuki et al., 2013; Wan et al., 2015).

Heat stress can induce oxidative stress. For instance, generation of ROS including singlet oxygen $\left({ }^{1} \mathrm{O}_{2}\right)$, superoxide radical $\left(\mathrm{O}^{2-}\right)$, hydrogen peroxide $\left(\mathrm{H}_{2} \mathrm{O}_{2}\right)$, and hydroxyl radical $\left(\mathrm{OH}^{-}\right)$are thought to be symptoms of cellular injury because of heat stress (Liu and Huang, 2000; Larkindale and Huang, 2004; Wang et al., 2012). Hsfs have been suggested to function as molecular sensors that directly sense and respond to the signals of ROS, which in turn activate the HSP expression and anti-oxidative genes. And HSF-binding motifs in the promoter region of genes associated with the ROS gene network have been detected (Miller and Mittler, 2006). Under heat stress the antioxidant enzyme system of plants is enhanced in response to increased ROS levels (Miller et al., 2008; Choudhury et al., 2013). In study of carnation (Dianthus caryophyllus) after short-term high temperature stress by RNA-seq, several genes encoding antioxidant enzymes including, APXs, AOX, thioredoxin, and glutathione $S$-transferase (GST) showed an increase in expressions (Wan et al., 2015). In the study herein, other than $A P X$ s and thioredoxin, we also identified several other genes involved in antioxidant responses, such as superoxide dismutases (SOD), CAT, POD, glutathione peroxidases (GPX), and $\mathrm{RBOH}$ proteins. Most of the genes were up-regulated, except some $P O D$ genes and $R B O H$ genes (Supplementary Table S8). SOD is the first line of defense against ROS, and is the key enzyme to scavenge $\mathrm{O}_{2}{ }^{-}$produced in the cells by catalyzing superoxide dismutation into hydrogen peroxide and oxygen. There are three different types of SOD isoforms according to their metal cofactors, namely Mn-SOD in mitochondria, Fe-SOD in chloroplasts, and $\mathrm{Cu} / \mathrm{Zn}-\mathrm{SOD}$ in cytosol and chloroplasts (Blokhina et al., 2003; Wahid et al., 2007). Here the expression levels of three mitochondrial $\mathrm{Mn}$-SODs, three chloroplastic $\mathrm{Fe}$ SODs, and one chloroplastic $\mathrm{Cu} / \mathrm{Zn}$-SOD were found to be increased at various degrees. SOD is known to be induced in different plants under heat stress (Larkindale and Huang, 2004). In plants, $\mathrm{H}_{2} \mathrm{O}_{2}$ is finely regulated by CAT and a group of peroxidases localized in nearly all compartments of plant cells, including APX and GPX (Blokhina et al., 2003; Ishikawa and Shigeoka, 2008; Gill and Tuteja, 2010). Catalase is indispensable for ROS detoxification during stressed conditions, and it is important in removing $\mathrm{H}_{2} \mathrm{O}_{2}$ generated in peroxisomes by oxidases participating in b-oxidation of fatty acids, purine catabolism and photorespiration (Garg and Manchanda, 2009; Saed-Moucheshi et al., 2014). Heat stress usually stimulates both the CAT activity and gene expression (Sairam et al., 2000; Lin et al., 2010). Here we found both CAT1 and CAT2 were upregulated in response to heat stress. GPX are a family of diverse isozymes using GSH to reduce lipid hydroperoxides and $\mathrm{H}_{2} \mathrm{O}_{2}$, and therefore protect plant cells from oxidative stress (Noctor et al., 2002). In Arabidopsis, there are seven GPX in cytosol, chloroplast, mitochondria and endoplasmic reticulum, named AtGPX1-AtGPX7 (Millar et al., 2003). In the study here, five GPXs were significantly up-regulated, and one was down-regulated. Thioredoxins are a class of small redox proteins known to play important roles in redox signaling and other biological processes (Arner and Holmgren, 2000; Dos Santos and Rey, 2006). Our study found a total of 18 unigenes encoding thioredoxin or thioredoxin-like proteins. Among of all the 18 thioredoxins, 13 of them were induced by heat stress. This result indicated thioredoxins could be one of the dominant antioxidants present in plants during heat shock, which is in agreement with previous studies in tobacco (Nicotiana tabacum) and carnation (Rizhsky et al., 2002; Wan et al., 2015).

Respiratory burst oxidase homologs gene family encode $\mathrm{NADPH}$ oxidase that generate super oxide and function in ROS promoted stress reactions and signaling (Jiang et al., 2011; Demidchik, 2015). Available data suggest that NADPH oxidase activity is required during stress primarily for the following four physiological and biochemical functions: (1) adjusting gene expression and metabolism by recognizing stress factor and its intensity; (2) stomatal closure under drought; (3) triggering the programed cell death; and (4) central "processor" of the signals of stress, defense and development (Torres and Dangl, 2005; Demidchik, 2015). There are 10 genes in Arabidopsis $(A t R B O H A-J)$ and 9 in rice. It exists in other plant species as well (Torres and Dangl, 2005; Kawahara et al., 2007). Here six unigenes were identified as $\mathrm{RBOH}$, and their expressions were mainly down-regulated, indicating a reduced ROS production after $6 \mathrm{~h}$ heat stress. Reactive oxygen species may act as signal molecules for plant growth and development, but excessive ROS are detrimental and can cause the autocatalytic peroxidation of pigments and membrane lipids, which leads to the loss of semi-permeability of membranes and modifies their functions (Senthil-Kumar et al., 2007; Wahid et al., 2007). Owing to the biological paradox, ROS levels are normally well regulated by their generation rate and the degradation rate as affected 
by the ROS scavenging capacity of antioxidant enzymes and antioxidants (Asada, 1999; Blokhina et al., 2003). In this respect, the changes of antioxidant related genes under heat stress showed a systematic response to maintain cellular homeostasis of ROS.

Photosynthesis known to be sensitive to environment stresses, and heat stress affect plant photosynthesis negatively (Mathur et al., 2014). For instance, 1 day high temperature at $35^{\circ} \mathrm{C}$ decreased canopy photosynthesis of creeping bentgrass ( $\mathrm{Xu}$ and Huang, 2000). Photochemical reactions in thylakoid lamellae and carbon metabolism in chloroplast stroma have been indicated as the major injury sites under heat stress (Wahid et al., 2007). Here KEGG pathway analysis revealed that 'photosynthesis,' 'photosynthesis - antenna proteins', and 'carbon fixation in photosynthetic organisms' were the most significantly enriched groups (Figures 5, 6).

The photosystem II (PSII) reaction center core consists of two chlorophyll binding proteins, D1 and D2, which are encoded by chloroplast $P s b A$ and $P s b D$ genes, respectively (Thum et al., 2001; Stroch et al., 2004; Armbruster et al., 2010). The D2 protein is needed for the assembly of a stable PSII complex. And it generates non-radiative energy dissipation, which is a very effective mechanism to protect the PSII from photodamage (Stroch et al., 2004; Song et al., 2014). Sane et al. (2002) suggested that D2 protein accumulation may promote resistance to high excitation stress induced by exposure to either high light or low temperature. Here we observed an up-regulation of $P s b D$ after heat stress, but not PsbA. Song et al. (2014) also reported a significant up-regulation of $P s b D$ at $6 \mathrm{~h}$ of heat treatment. The result suggested that $P s b D$ might be associated with mechanisms protecting against photodamage of perennial ryegrass under the stress condition.

Photosystem II inactivation by heat may be followed by dissociation of LHC II (light-harvesting complex II) (Mathur et al., 2014). The light-harvesting chlorophyll a/b binding proteins (LHCB and LHCA) are the apoproteins of the PSII and PSI light-harvesting complex, which are generally associated with xanthophylls and chlorophyll and serve as the antenna complex (Jansson, 1999). Expression of the LHC genes is regulated by multiple environmental and developmental cues, including light, chloroplast retrograde signal, circadian clock, abscisic acid (ABA), oxidative stress, and heat stress (Humbeck and Krupinska, 2003; Staneloni et al., 2008; Xu et al., 2012). Stresses mainly down-regulated the expression of LHC genes (Heddad and Adamska, 2000; Qin et al., 2008; Song et al., 2014; Kong et al., 2016), but some of the LHC genes were also found to be up-regulated, such as $L H C B 2.1$ in poplar exposed to high temperature treatment $\left(42^{\circ} \mathrm{C}\right)$ for $6 \mathrm{~h}$ (Song et al., 2014). Here two LHC genes (Lhcal and Lhcb4) were up-regulated, and the rest are largely unchanged, indicating that the negative effects on PSII and PSI from current heat stress treatment $\left(35^{\circ} \mathrm{C}, 6 \mathrm{~h}\right)$ were moderate. It is known that plant heat stress responses depending on both the stress intensity and duration (Schulze et al., 2005). Qin et al. (2008) reported that 21 probe sets of LHC proteins were repressed by heat particularly in the $24-\mathrm{h} 40^{\circ} \mathrm{C}$ heat treatments, and pointed out that long-term heat stress damaged the photosystems more severely. In a proteomic study of alfalfa under heat stress, three chlorophyll a/b binding proteins were up-regulated at $24 \mathrm{~h}$, but then decreased as the stress prolonged (72 h) (Li W. et al., 2013).

Heat stress not only affects photosynthesis by inactivating photosystems (e.g., PSII and PSI), but also by adjusting carbon fixation (Wahid et al., 2007). Here genes encoding enzymes normally involved in C4-dicarboxylic acid cycle and/or crassulacean acid metabolism (CAM) were significantly affected with two genes up-regulated (AST and PEPCK), and the other two down-regulated ( $P P D K$ and $N A D-M E)$. This is interested since perennial ryegrass is a cool-season/C3 grass species. The PEPCK enzyme seems to be ubiquitous in plants, including C3 plant species (Leegood and Walker, 2003; Christin et al., 2009; Aldous et al., 2014). The PEPCK isoform involved in C4 photosynthesis is expressed in bundle-sheath cells, and it catalyzes the release of $\mathrm{CO}_{2}$ from oxaloacetate for the Calvin cycle, while AST catalyzes the reversible conversion of aspartate to oxaloacetate. In C3 plants, PEPCK also plays roles in gluconeogenesis, liberating carbon from breakdown of lipids and making the energy available for seedling growth and development (Trevanion et al., 1995; Christin et al., 2009), and in the metabolism of nitrogenous compounds in seeds (Delgado-Alvarado et al., 2007). Along with PEPCK, NAD$\mathrm{ME}$ is another decarboxylation enzyme used in the inorganic carbon concentrating mechanisms of $\mathrm{C} 4$ and CAM plants, which oxidized malate to pyruvate and $\mathrm{CO}_{2}$. Non-photosynthetic isoforms of NAD-ME participates in the respiration of malate in the tricarboxylic acid cycle (Maier et al., 2011), and in Arabidopsis the malic enzyme has a major impact on nocturnal metabolism (Tronconi et al., 2008). PPDK participates in pyruvate metabolism and carbon fixation by catalyzing the reversible conversion of pyruvate to phosphoenolpyruvate (PEP) (Chastain et al., 2011). In C3 plants, PPDK primarily functions as an ancillary glycolytic enzyme to modulate carbon metabolism (Chastain et al., 2006; Hennen-Bierwagen et al., 2009; Taylor et al., 2010). In addition, it can also facilitate nitrogen remobilization into glutamine in senescing leaves (Taylor et al., 2010). Doubnerová and Ryšlavá (2011) suggested the functions of non-photosynthetic counterparts of C4 photosynthesis enzymes seem to be more important for plants under stresses than under optimal conditions, such as NADP-ME and PPDK. Variation of some of the genes under heat stress have been reported, and heat stress diminishes the activities of NAD(P)-ME and PPDK (Farooq et al., 2011). For instance, Wang et al. (2015) reported a reduction in PPDK activities in rice due to high temperature, which is confirmed further at both transcription and translation levels. Transcripts of AST were decreased by increased growth temperature (Duke and Doehlert, 1996). The expression changes of the four genes here might be a metabolic modulation in response to heat stress, and their exact mechanism would need further researches in future.

Plant hormones have important roles in regulating plant growth, development, and environmental stress tolerance (Davies, 2004). Under heat stress hormone homeostasis is altered, including hormone stability, biosynthesis, total contents, and compartmentalization (Maestri et al., 2002). Although the involvement of hormones in plant thermo-tolerance is complex and the exact signal pathway of hormones under heat is yet 
mostly unclear, many studies have shown that optimizing status of certain hormones can enhance plant thermo-tolerance (Kotak et al., 2007; Wahid et al., 2007). Cytokinins (CKs) are a group of plant hormones that play an important role in many growth and developmental processes, including promoting cell division and differentiation, enhancing chloroplast development, and counteraction of senescence (Mok and Mok, 2001). Heat stress affects CK synthesis adversely, with the reduction of CKs being reported in different species under stress, such as wild tobacco (Nicotiana rustica), and common bean (Phaseolus vulgaris) (Itai et al., 1973), winter rape (Brassica napus L.) (Zhou and Leul, 1999), and creeping bentgrass (Xu and Huang, 2007). Moreover, application of exogenous CKs has been shown to have effects on alleviating plant heat injury (Skogqvist, 1974; Liu and Huang, 2002; Wang et al., 2013). Adenine isopentenyl transferase (IPT) is a key enzyme catalyzing the rate-limiting step in CK biosynthesis (Sakakibara, 2006). Several studies found SAG12-ipt and HSPipt transgenic creeping bentgrass showed improved thermotolerance compared to control plants ( $\mathrm{Xu}$ et al., 2009). Here we found IPT was down-regulated in perennial ryegrass under heat stress. In the meanwhile, a gene (cis-ZOG) involved in the $\mathrm{O}$-glycosylation of $\mathrm{CKs}$ and converting active CKs into inactive or less active $O$-glucosides was up-regulated under heat stress (Supplementary Figure S1). All the results indicated a possible reduction of active CKs in perennial ryegrass under heat stress.

Target of rapamycin (TOR) is a Ser/Thr protein kinase that is structurally and functionally conserved among eukaryotes (yeast, plants, animals, and etc.) (Wullschleger et al., 2006). In mammals, TOR controls growth in response to growth factors (e.g., insulin), nutrients (e.g., amino acids), and cellular energy (ATP) (Loewith and Hall, 2011). And large amount of studies have been focused on the role of mTOR (mammalian TOR) in tumor development and cancer therapies (Baldo et al., 2008; Kim et al., 2016). In higher plants, TOR plays an evolutionarily conserved role in the transcription regulation of genes involved in anabolic and catabolic processes (John et al., 2011; Xiong et al., 2013). More recently, TOR was suggested to play a crucial role in modulating photosynthesis and phytohormone signaling in Arabidopsis, including light reaction, carbon fixation and plant hormone (auxin, ABA, brassinosteroid, and CK) signaling transduction (Dong et al., 2015; Deng et al., 2016). Here we observed an up-regulation of TOR under heat stress, which might be related to its role as a central controller of cell growth and metabolism (Supplementary Figure S2) (Hall, 2008).

In summary, the de novo assembly of perennial ryegrass transcriptome obtained more total and annotated unigenes

\section{REFERENCES}

Ada, N., Norberto, E. P., and Sergio, M. (1987). Early and late heat shock proteins in wheats and other cereal species. Plant Physiol. 84, 1378-1384. doi: 10.1104/ pp.84.4.1378

Agarwal, M., Sahi, C., Katiyar-Agarwal, S., Agarwal, S., Young, T., Gallie, D. R., et al. (2003). Molecular characterization of rice hsp101: complementation of yeast hsp104 mutation by disaggregation of protein granules and differential expression in indica and japonica rice types. Plant Mol. Biol. 51, 543-553. doi: 10.1023/A:1022324920316 compared to previously published ones. Most of the DEGs identified in perennial ryegrass under heat stress were relatively common to the genes reported to be responsive to heat stress in plants, including HSFs, HSPs, and antioxidant related genes. In the meanwhile, we also identified four gene candidates mainly involved in $\mathrm{C} 4$ carbon fixation, and one TOR gene. Their exact role in plant heat stress response would warrant further studies.

\section{AUTHOR CONTRIBUTIONS}

Conceived and designed the experiments: KW and WZ. Performed the experiments: YL, JT, KH, TS, and XD. Analyzed the data: YL, JT, KW, and WZ. Wrote the paper: KW. All authors reviewed and approved the final manuscript.

\section{ACKNOWLEDGMENTS}

We thank the National Natural Science Foundation of China (31472140), China National Key Technology Support Program (2014BAD23B03-02), and the Fundamental Research Funds for the Central Universities of China (2017QC128) for financial support.

\section{SUPPLEMENTARY MATERIAL}

The Supplementary Material for this article can be found online at: http://journal.frontiersin.org/article/10.3389/fpls.2017.01032/ full\#supplementary-material

FIGURE S1 | The zeatin biosynthesis pathway enriched by KEGG analysis. Gene/protein names in a red and blue box represent up-regulation and down-regulation under heat stress, respectively. EC:2.5.1.27, 2.5.1.112, adenylate dimethylallyltransferase (IPT, cytokinin synthase); EC:2.4.1.215, cis-zeatin O-glucosyltransferase (Cis-ZOG); EC:2.5.1.75, tRNA dimethylallyltransferase.

FIGURE S2 | The mTOR (mammalian target of rapamycin) signaling pathway enriched by KEGG analysis. Gene/protein names in a red and blue box represent up-regulation and down-regulation under heat stress, respectively. EC:2.7.11.1, serine/threonine-protein kinase mTOR.

FIGURE S3 | Linear regression analysis between Quantitative Real-Time PCR (qRT-PCR) and RNA-seq results $\left(r^{2}=0.8739\right)$ for 16 genes. $X$-axis numbers represent the fold change values of qRT-PCR results. $Y$-axis numbers represent the fold change values of RNA-seq results.

FIGURE S4 | qRT-PCR verification of the 16 randomly selected DEGS (differentially expressed genes). Error bars indicate standard deviation. 
Arner, E. S. J., and Holmgren, A. (2000). Physiological functions of thioredoxin and thioredoxin reductase. Eur. J. Biochem. 267, 6102-6109. doi: 10.1046/j.14321327.2000.01701.x

Asada, K. (1999). The water-water cycle in chloroplasts: scavenging of active oxygens and dissipation of excess photons. Annu. Rev. Plant Physiol. Plant Mol. Biol. 50, 601-639. doi: 10.1146/annurev.arplant.50.1.601

Baldo, P., Cecco, S., Giacomin, E., Lazzarini, R., Rose, B., and Marastoni, S. (2008). mTOR pathway and mtor inhibitors as agents for cancer therapy. Curr. Cancer Drug. Targets 8, 647-665. doi: 10.2174/156800908786733513

Baniwal, S. K., Bharti, K., Chan, K. Y., Fauth, M., Ganguli, A., Kotak, S., et al. (2004). Heat stress response in plants: a complex game with chaperones and more than twenty heat stress transcription factors. J. Biosci. 29, 471-487. doi: $10.1007 / \mathrm{BF} 02712120$

Barnes, B. D., Kopecky, D., Lukaszewski, A. J., and Baird, J. H. (2014). Evaluation of turf-type interspecific hybrids of meadow fescue with perennial ryegrass for improved stress tolerance. Crop Sci. 54, 355-365. doi: 10.2135/cropsci2013.03. 0198

Bharti, K., and Nover, L. (2002). "Heat stress-induced signalling," in Plant Signal Transduction: Frontiers in Molecular Biology, eds D. Scheel and C. Wasternack (Oxford: Oxford University Press), 74-115.

Bita, C. E., Zenoni, S., Vriezen, W. H., Mariani, C., Pezzotti, M., and Gerats, T. (2011). Temperature stress differentially modulates transcription in meiotic anthers of heat-tolerant and heat-sensitive tomato plants. BMC Genomics 12:384. doi: 10.1186/1471-2164-12-384

Blokhina, O., Virolainen, E., and Fagerstedt, K. V. (2003). Antioxidants, oxidative damage and oxygen deprivation stress: a review. Ann. Bot. 91, 179-194. doi: $10.1093 / \mathrm{aob} / \mathrm{mcf} 118$

Casaretto, J. A., El-Kereamy, A., Zeng, B., Stiegelmeyer, S. M., Chen, X., Bi, Y.M., et al. (2016). Expression of OsMYB55 in maize activates stress-responsive genes and enhances heat and drought tolerance. BMC Genomics 17:312. doi: 10.1186/s12864-016-2659-5

Chastain, C. J., Failing, C. J., Manandhar, L., Zimmerman, M. A., Lakner, M. M., and Nguyen, T. H. T. (2011). Functional evolution of C-4 pyruvate, orthophosphate dikinase. J. Exp. Bot. 62, 3083-3091. doi: 10.1093/jxb/err058

Chastain, C. J., Heck, J. W., Colquhoun, T. A., Voge, D. G., and Gu, X.-Y. (2006). Posttranslational regulation of pyruvate, orthophosphate dikinase in developing rice (Oryza sativa) seeds. Planta 224, 924-934. doi: 10.1007/s00425006-0259-3

Chen, J., Thammina, C., Li, W., Yu, H., Yer, H., El-Tanbouly, R., et al. (2016). Isolation of prostrate turfgrass mutants via screening of dwarf phenotype and characterization of a perennial ryegrass prostrate mutant. Hortic. Res. 3, 16003-16003. doi: 10.1038/hortres.2016.3

Chen, S., and Li, H. (2017). Heat stress regulates the expression of genes at transcriptional and post-transcriptional levels, revealed by RNA-seq in Brachypodium distachyon. Front. Plant Sci. 7:2067. doi: 10.3389/fpls.2016. 02067

Cheng, L., Sun, R.-R., Wang, F.-Y., Peng, Z., Kong, F.-L., Wu, J., et al. (2012). Spermidine affects the transcriptome responses to high temperature stress in ripening tomato fruit. J. Zhejiang Univ. Sci. B 13, 283-297. doi: 10.1631/jzus. B1100060

Choudhury, S., Panda, P., Sahoo, L., and Panda, S. K. (2013). Reactive oxygen species signaling in plants under abiotic stress. Plant Signal. Behav. 8:e23681. doi: $10.4161 /$ psb. 23681

Christin, P.-A., Petitpierre, B., Salamin, N., Buechi, L., and Besnard, G. (2009). Evolution of C-4 phosphoenolpyruvate carboxykinase in grasses, from genotype to phenotype. Mol. Biol. Evol. 26, 357-365. doi: 10.1093/molbev/msn255

Davies, P. J. (2004). Plant Hormones: Biosynthesis, Signal Transduction, Action! Berlin: Springer.

Delgado-Alvarado, A., Walker, R. P., and Leegood, R. C. (2007). Phosphoenolpyruvate carboxykinase in developing pea seeds is associated with tissues involved in solute transport and is nitrogen-responsive. Plant Cell Environ. 30, 225-235. doi: 10.1111/j.1365-3040.2006.01622.x

Demidchik, V. (2015). Mechanisms of oxidative stress in plants: from classical chemistry to cell biology. Environ. Exp. Bot. 109, 212-228. doi: 10.1016/j. envexpbot.2014.06.021

Deng, K., Yu, L., Zheng, X., Zhang, K., Wang, W., Dong, P., et al. (2016). Target of rapamycin is a key player for auxin signaling transduction in Arabidopsis. Front. Plant Sci. 7:291. doi: 10.3389/fpls.2016.00291
Dong, P., Xiong, F., Que, Y., Wang, K., Yu, L., Li, Z., et al. (2015). Expression profiling and functional analysis reveals that TOR is a key player in regulating photosynthesis and phytohormone signaling pathways in Arabidopsis. Front. Plant Sci. 6:677. doi: 10.3389/fpls.2015.00677

Dos Santos, C. V., and Rey, P. (2006). Plant thioredoxins are key actors in the oxidative stress response. Trends Plant Sci. 11, 329-334. doi: 10.1016/j.tplants. 2006.05.005

Doubnerová, V., and Ryšlavá, H. (2011). What can enzymes of C4 photosynthesis do for C3 plants under stress? Plant Sci. 180, 575-583. doi: 10.1016/j.plantsci. 2010.12.005

Downs, C. A., Heckathorn, S. A., Bryan, J. K., and Coleman, J. S. (1998). The methionine-rich low-molecular-weight chloroplast heat-shock protein: evolutionary conservation and accumulation in relation to thermotolerance. Am. J. Bot. 85, 175-183. doi: 10.2307/2446306

Duke, E. R., and Doehlert, D. C. (1996). Effects of heat stress on enzyme activities and transcript levels in developing maize kernels grown in culture. Environ. Exp. Bot. 36, 199-208. doi: 10.1016/0098-8472(96)01004-0

Dutra, S. M. F., Von Pinho, E. V. R., Santos, H. O., Lima, A. C., Von Pinho, R. G., and Carvalho, M. L. M. (2015). Genes related to high temperature tolerance during maize seed germination. Genet. Mol. Res. 14, 18047-18058. doi: 10.4238/2015.December.22.31

Farooq, M., Bramley, H., Palta, J. A., and Siddique, K. H. M. (2011). Heat stress in wheat during reproductive and grain-filling phases. Critic. Rev. Plant Sci. 30, 491-507. doi: 10.1080/07352689.2011.615687

Farrell, J. D., Byrne, S., Paina, C., and Asp, T. (2014). De Novo assembly of the perennial ryegrass transcriptome using an rna-seq strategy. PLoS ONE 9:e103567. doi: 10.1371/journal.pone.0103567

Frey, F. P., Urbany, C., Huettel, B., Reinhardt, R., and Stich, B. (2015). Genomewide expression profiling and phenotypic evaluation of European maize inbreds at seedling stage in response to heat stress. BMC Genomics 16:123. doi: 10.1186/ s12864-015-1282-1

Gao, J., Sun, L., Yang, X., and Liu, J.-X. (2013). Transcriptomic analysis of cadmium stress response in the heavy metal hyperaccumulator Sedum alfredii Hance. PLoS ONE 8:e64643. doi: 10.1371/journal.pone.0064643

Garg, N., and Manchanda, G. (2009). ROS generation in plants: boon or bane? Plant Biosyst. 143, 81-96. doi: 10.1080/11263500802633626

Gill, S. S., and Tuteja, N. (2010). Reactive oxygen species and antioxidant machinery in abiotic stress tolerance in crop plants. Plant Physiol. Biochem. 48, 909-930. doi: 10.1016/j.plaphy.2010.08.016

Ginzberg, I., Barel, G., Ophir, R., Tzin, E., Tanami, Z., Muddarangappa, T., et al. (2009). Transcriptomic profiling of heat-stress response in potato periderm. J. Exp. Bot. 60, 4411-4421. doi: 10.1093/jxb/erp281

Grabherr, M. G., Haas, B. J., Yassour, M., Levin, J. Z., Thompson, D. A., Amit, I., et al. (2011). Full-length transcriptome assembly from RNA-Seq data without a reference genome. Nat. Biotechnol. 29, 644-U130. doi: 10.1038/nbt.1883

Guo, J., Wu, J., Ji, Q., Wang, C., Luo, L., Yuan, Y., et al. (2008). Genome-wide analysis of heat shock transcription factor families in rice and Arabidopsis. J. Genet. Genomics 35, 105-118. doi: 10.1016/S1673-8527(08)60016-8

Guo, M., Liu, J.-H., Ma, X., Luo, D.-X., Gong, Z.-H., and Lu, M.-H. (2016). The plant heat stress transcription factors (HSFs): structure, regulation, and function in response to abiotic stresses. Front. Plant Sci. 7:114. doi: 10.3389/ fpls.2016.00114

Hall, M. N. (2008). mTOR-What does it do? Transpl. Proc. 40, S5-S8. doi: 10.1038/ ncomms 13493

Hasanuzzaman, M., Nahar, K., Alam, M. M., Roychowdhury, R., and Fujita, M. (2013). Physiological, biochemical, and molecular mechanisms of heat stress tolerance in plants. Int. J. Mol. Sci. 14, 9643-9684. doi: 10.3390/ijms14059643

Heddad, M., and Adamska, I. (2000). Light stress-regulated two-helix proteins in Arabidopsis thaliana related to the chlorophyll a/b-binding gene family. Proc. Natl. Acad. Sci. U.S.A. 97, 3741-3746. doi: 10.1073/pnas.97.7.3741

Hennen-Bierwagen, T. A., Lin, Q., Grimaud, F., Planchot, V., Keeling, P. L., James, M. G., et al. (2009). Proteins from multiple metabolic pathways associate with starch biosynthetic enzymes in high molecular weight complexes: a model for regulation of carbon allocation in maize amyloplasts. Plant Physiol. 149, 1541-1559. doi: 10.1104/pp.109.135293

Hong, S. W., and Vierling, E. (2001). Hsp101 is necessary for heat tolerance but dispensable for development and germination in the absence of stress. Plant $\mathrm{J}$. 27, 25-35. doi: 10.1046/j.1365-313x.2001.01066.x 
Hu, T., Sun, X., Zhang, X., Nevo, E., and Fu, J. (2014). An RNA sequencing transcriptome analysis of the high-temperature stressed tall fescue reveals novel insights into plant thermotolerance. BMC Genomics 15:1147. doi: 10.1186/ 1471-2164-15-1147

Humbeck, K., and Krupinska, K. (2003). The abundance of minor chlorophyll a/bbinding proteins CP29 and $\mathrm{LHCl}$ of barley (Hordeum vulgare $\mathrm{L}$.) during leaf senescence is controlled by light. J. Exp. Bot. 54, 375-383. doi: 10.1093/jxb/ erg012

Hyun, T., Rim, Y., Jang, H.-J., Kim, C., Park, J., Kumar, R., et al. (2012). De novo transcriptome sequencing of Momordica cochinchinensis to identify genes involved in the carotenoid biosynthesis. Plant Mol. Biol. 79, 413-427. doi: 10.1007/s11103-012-9919-9

IPCC (2014). "Climate change 2014: synthesis report," in Contribution of Working Groups I, II and III to the Fifth Assessment Report of the Intergovernmental Panel on Climate Change, eds R. K. Pachauri and L. A. Meyer (Geneva: IPCC).

Iseli, C., Jongeneel, C. V., and Bucher, P. (1999). "ESTScan: a program for detecting, evaluating, and reconstructing potential coding regions in EST sequences," in Proceedings International Conference on Intelligent Systems for Molecular Biology, Heidelberg, 138-148.

Ishikawa, T., and Shigeoka, S. (2008). Recent advances in ascorbate biosynthesis and the physiological significance of ascorbate peroxidase in photosynthesizing organisms. Biosci. Biotechnol. Biochem. 72, 1143-1154. doi: 10.1271/bbb. 80062

Itai, C. H. A. N., Ben-Zioni, A. L. I. Z., and Ordin, L. A. W. R. (1973). Correlative changes in endogenous hormone levels and shoot growth induced by short heat treatments to the root. Physiol. Plant 29, 355-360. doi: 10.1111/j.1399-3054. 1973.tb04830.x

Jansson, S. (1999). A guide to the Lhc genes and their relatives in Arabidopsis. Trends Plant Sci. 4, 236-240. doi: 10.1016/S1360-1385(99)01419-3

Jiang, F., Zhang, Y., and Dusting, G. J. (2011). NADPH oxidase-mediated redox signaling: roles in cellular stress response, stress tolerance, and tissue repair. Pharmacol. Rev. 63, 218-242. doi: 10.1124/pr.110.002980

Jiang, Y. W., and Huang, B. R. (2001). Physiological responses to heat stress alone or in combination with drought: a comparison between tall fescue and perennial ryegrass. HortScience 36, 682-686.

John, F., Roffler, S., Wicker, T., and Ringli, C. (2011). Plant TOR signaling components. Plant Sig. Behav. 6, 1700-1705. doi: 10.4161/psb.6.11. 17662

Kanehisa, M., Araki, M., Goto, S., Hattori, M., Hirakawa, M., Itoh, M., et al. (2008). KEGG for linking genomes to life and the environment. Nucleic Acids Res. 36, D480-D484.

Kant, P., Gordon, M., Kant, S., Zolla, G., Davydov, O., Heimer, Y. M., et al. (2008). Functional-genomics-based identification of genes that regulate Arabidopsis responses to multiple abiotic stresses. Plant Cell Environ. 31, 697-714. doi: 10.1111/j.1365-3040.2008.01779.x

Kauffman, G. L., Kneivel, D. P., and Watschke, T. L. (2007). Effects of a biostimulant on the heat tolerance associated with photosynthetic capacity, membrane thermostability, and polyphenol production of perennial ryegrass. Crop Sci. 47, 261-267. doi: 10.2135/cropsci2006.03.0171

Kawahara, T., Quinn, M. T., and Lambeth, J. D. (2007). Molecular evolution of the reactive oxygen-generating NADPH oxidase (Nox/Duox) family of enzymes. BMC Evol. Biol. 7:109. doi: 10.1186/1471-2148-7-109

Kim, L. C., Cook, R. S., and Chen, J. (2016). mTORC1 and mTORC2 in cancer and the tumor microenvironment. Oncogene 36, 2191-2201. doi: 10.1038/onc. 2016.363

Knight, C. A., and Ackerly, D. D. (2001). Correlated evolution of chloroplast heat shock protein expression in closely related plant species. Am. J. Bot. 88, 411-418. doi: 10.2307/2657105

Kong, F., Zhou, Y., Sun, P., Cao, M., Li, H., and Mao, Y. (2016). Identification of light-harvesting chlorophyll a/b-binding protein genes of Zostera marina L. and their expression under different environmental conditions. J. Ocean Univ. China 15, 152-162. doi: 10.1007/s11802-016-2688-3

Kotak, S., Larkindale, J., Lee, U., Von Koskull-Döring, P., Vierling, E., and Scharf, K.-D. (2007). Complexity of the heat stress response in plants. Curr. Opin. Plant Biol. 10, 310-316. doi: 10.1016/j.pbi.2007.04.011

Larkindale, J., and Huang, B. (2004). Thermotolerance and antioxidant systems in Agrostis stolonifera: involvement of salicylic acid, abscisic acid, calcium, hydrogen peroxide, and ethylene. J. Plant Physiol. 161, 405-413. doi: 10.1078/ 0176-1617-01239

Larkindale, J., and Vierling, E. (2008). Core genome responses involved in acclimation to high temperature. Plant Physiol. 146, 748-761. doi: 10.1104/pp. 107.112060

Lee, B. H., Won, S. H., Lee, H. S., Miyao, M., Chung, W. I., Kim, I. J., et al. (2000). Expression of the chloroplast-localized small heat shock protein by oxidative stress in rice. Gene 245, 283-290. doi: 10.1016/S0378-1119(00)00043-3

Leegood, R. C., and Walker, R. P. (2003). Regulation and roles of phosphoenolpyruvate carboxykinase in plants. Arch. Biochem. Biophys. 414, 204-210. doi: 10.1016/S0003-9861(03)00093-6

Leone, A., Perrotta, C., and Maresca, B. (2003). "Plant tolerance to heat stress: current strategies and new emergent insights," in Abiotic Stresses in Plants, eds L. S. Di Toppi and B. Pawlik-SkowroniSka (Dordrecht: Kluwer Academic Publishers), 1-22.

Li, B., and Dewey, C. N. (2011). RSEM: accurate transcript quantification from RNA-Seq data with or without a reference genome. BMC Bioinformatics 12:323. doi: 10.1186/1471-2105-12-323

Li, W., Wei, Z., Qiao, Z., Wu, Z., Cheng, L., and Wang, Y. (2013). Proteomics analysis of alfalfa response to heat stress. PLOS ONE 8:e82725. doi: 10.1371/ journal.pone.0082725

Li, Z., Hu, Q., Zhou, M., Vandenbrink, J., Li, D., Menchyk, N., et al. (2013). Heterologous expression of OsSIZ1, a rice SUMO E3 ligase, enhances broad abiotic stress tolerance in transgenic creeping bentgrass. Plant Biotechnol. J. 11, 432-445. doi: 10.1111/pbi.12030

Lin, K.-H., Huang, H.-C., and Lin, C.-Y. (2010). Cloning, expression and physiological analysis of broccoli catalase gene and Chinese cabbage ascorbate peroxidase gene under heat stress. Plant Cell Rep. 29, 575-593. doi: 10.1007/ s00299-010-0846-4

Liu, X. H., and Huang, B. R. (2002). Cytokinin effects on creeping bentgrass response to heat stress: II. Leaf senescence and antioxidant metabolism. Crop Sci. 42, 466-472. doi: 10.2135/cropsci2002.0466

Liu, X. Z., and Huang, B. R. (2000). Heat stress injury in relation to membrane lipid peroxidation in creeping bentgrass. Crop Sci. 40, 503-510. doi: 10.2135/ cropsci2000.402503x

Livak, K. J., and Schmittgen, T. D. (2001). Analysis of relative gene expression data using real-time quantitative PCR and the 2(T)(-Delta Delta C) method. Methods 25, 402-408. doi: 10.1006/meth.2001.1262

Loewith, R., and Hall, M. N. (2011). Target of rapamycin (TOR) in nutrient signaling and growth control. Genetics 189, 1177-1201. doi: 10.1534/genetics. 111.133363

Lohmann, C., Eggers-Schumacher, G., Wunderlich, M., and Schoffl, F. (2004). Two different heat shock transcription factors regulate immediate early expression of stress genes in Arabidopsis. Mol. Genet. Genomics 271, 11-21. doi: 10.1007/ s00438-003-0954-8

Maestri, E., Klueva, N., Perrotta, C., Gulli, M., Nguyen, H. T., and Marmiroli, N. (2002). Molecular genetics of heat tolerance and heat shock proteins in cereals. Plant Mol. Biol. 48, 667-681. doi: 10.1023/A:1014826730024

Maier, A., Zell, M. B., and Maurino, V. G. (2011). Malate decarboxylases: evolution and roles of NAD(P)-ME isoforms in species performing C-4 and C-3 photosynthesis. J. Exp. Bot. 62, 3061-3069. doi: 10.1093/jxb/err024

Mao, X. Z., Cai, T., Olyarchuk, J. G., and Wei, L. P. (2005). Automated genome annotation and pathway identification using the KEGG Orthology (KO) as a controlled vocabulary. Bioinformatics 21, 3787-3793. doi: 10.1093/ bioinformatics/bti430

Mathur, S., Agrawal, D., and Jajoo, A. (2014). Photosynthesis: response to high temperature stress. J. Photochem. Photobiol. Biol. 137, 116-126. doi: 10.1016/ j.jphotobiol.2014.01.010

Millar, A. H., Mittova, V., Kiddle, G., Heazlewood, J. L., Bartoli, C. G., Theodoulou, F. L., et al. (2003). Control of ascorbate synthesis by respiration and its implications for stress responses. Plant Physiol. 133, 443-447. doi: 10.1104/pp. 103.028399

Miller, G., Shulaev, V., and Mittler, R. (2008). Reactive oxygen signaling and abiotic stress. Physiol. Plant. 133, 481-489. doi: 10.1111/j.1399-3054.2008.01090.x

Miller, G. A. D., and Mittler, R. O. N. (2006). Could heat shock transcription factors function as hydrogen peroxide sensors in plants? Ann. Bot. 98, 279-288. doi: $10.1093 / \mathrm{aob} / \mathrm{mcl} 107$ 
Minner, D. D., Dernoeden, P. H., Wehner, D. J., and Mcintosh, M. S. (1983). Heat tolerance screening of field-grown cultivars of kentucky bluegrass and perennial ryegrass. Agron. J. 75, 772-775. doi: 10.2134/agronj1983. 00021962007500050012x

Mishra, S. K., Tripp, J., Winkelhaus, S., Tschiersch, B., Theres, K., Nover, L., et al. (2002). In the complex family of heat stress transcription factors, HSfA1 has a unique role as master regulator of thermotolerance in tomato. Genes Dev. 16, 1555-1567. doi: 10.1101/gad.228802

Mok, D. W. S., and Mok, M. C. (2001). Cytokinin metabolism and action. Annu. Rev. Plant Physiol. Plant Mol. Biol. 52, 89-118. doi: 10.1146/annurev.arplant. 52.1.89

Nejat, N., Cahill, D. M., Vadamalai, G., Ziemann, M., Rookes, J., and Naderali, N. (2015). Transcriptomics-based analysis using RNA-Seq of the coconut (Cocos nucifera) leaf in response to yellow decline phytoplasma infection. Mol. Genet. Genomics 290, 1899-1910. doi: 10.1007/s00438-015-1046-2

Nieto-Sotelo, J., Martinez, L. M., Ponce, G., Cassab, G. I., Alagon, A., Meeley, R. B., et al. (2002). Maize HSP101 plays important roles in both induced and basal thermotolerance and primary root growth. Plant Cell 14, 1621-1633. doi: 10.1105/tpc.010487

Nishizawa, A., Yabuta, Y., Yoshida, E., Maruta, T., Yoshimura, K., and Shigeoka, S. (2006). Arabidopsis heat shock transcription factor A2 as a key regulator in response to several types of environmental stress. Plant J. 48, 535-547. doi: 10.1111/j.1365-313X.2006.02889.X

Nishizawa-Yokoi, A., Yoshida, E., Yabuta, Y., and Shigeoka, S. (2009). Analysis of the regulation of target genes by an Arabidopsis heat shock transcription factor, HsfA2. Biosci. Biotechnol. Biochem. 73, 890-895. doi: 10.1271/bbb.80809

Noctor, G., Gomez, L., Vanacker, H., and Foyer, C. H. (2002). Interactions between biosynthesis, compartmentation and transport in the control of glutathione homeostasis and signalling. J. Exp. Bot. 53, 1283-1304. doi: 10.1093/jexbot/53. 372.1283

Panchuk, I. I., Volkov, R. A., and Schoffl, F. (2002). Heat stress- and heat shock transcription factor-dependent expression and activity of ascorbate peroxidase in Arabidopsis. Plant Physiol. 129, 838-853. doi: 10.1104/pp.001362

Panikulangara, T. J., Eggers-Schumacher, G., Wunderlich, M., Stransky, H., and Schoffl, F. (2004). Galactinol synthase1. A novel heat shock factor target gene responsible for heat-induced synthesis of raffinose family oligosaccharides in Arabidopsis. Plant Physiol. 136, 3148-3158. doi: 10.1104/pp.104.042606

Penfield, S. (2008). Temperature perception and signal transduction in plants. New Phytol. 179, 615-628. doi: 10.1111/j.1469-8137.2008.02478.x

Pfeifer, M., Martis, M., Asp, T., Mayer, K. F. X., Lubberstedt, T., Byrne, S., et al. (2013). The perennial ryegrass genomezipper: targeted use of genome resources for comparative grass genomics. Plant Physiol. 161, 571-582. doi: 10.1104/pp. 112.207282

Pockley, A. G. (2003). Heat shock proteins as regulators of the immune response. Lancet 362, 469-476. doi: 10.1016/S0140-6736(03)14075-5

Preczewski, P. J., Heckathorn, S. A., Downs, C. A., and Coleman, J. S. (2000). Photosynthetic thermotolerance is quantitatively and positively correlated with production of specific heat-shock proteins among nine genotypes of Lycopersicon (tomato). Photosynthetica 38, 127-134. doi: 10.1023/A: 1026760311255

Qin, D., Wu, H., Peng, H., Yao, Y., Ni, Z., Li, Z., et al. (2008). Heat stressresponsive transcriptome analysis in heat susceptible and tolerant wheat (Triticum aestivum L.) by using wheat genome array. BMC Genomics 9:432. doi: 10.1186/1471-2164-9-432

Rizhsky, L., Liang, H. J., and Mittler, R. (2002). The combined effect of drought stress and heat shock on gene expression in tobacco. Plant Physiol. 130, 1143-1151. doi: 10.1104/pp.006858

Saed-Moucheshi, A., Shekoofa, A., and Pessarakli, M. (2014). Reactive oxygen species (ROS) generation and detoxifying in plants. J. Plant Nutr. 37, 1573-1585. doi: 10.1080/01904167.2013.868483

Sairam, R. K., Srivastava, G. C., and Saxena, D. C. (2000). Increased antioxidant activity under elevated temperatures: a mechanism of heat stress tolerance in wheat genotypes. Biol. Plant. 43, 245-251. doi: 10.1023/A:1002756311146

Sakakibara, H. (2006). Cytokinins: activity, biosynthesis, and translocation. Annu. Rev. Plant Biol. 57, 431-449. doi: 10.1146/annurev.arplant.57.032905.105231

Sane, P. V., Ivanov, A. G., Sveshnikov, D., Huner, N. P. A., and Oquist, G. (2002). A transient exchange of the photosystem II reaction center protein D1 : 1 with D1 : 2 during low temperature stress of Synechococcus sp PCC 7942 in the light lowers the redox potential of Q(B). J. Biol. Chem. 277, 32739-32745. doi: 10.1074/jbc.M200444200

Sarkar, N. K., Kim, Y.-K., and Grover, A. (2014). Coexpression network analysis associated with call of rice seedlings for encountering heat stress. Plant Mol. Biol. 84, 125-143. doi: 10.1007/s11103-013-0123-3

Sathish, P., Withana, N., Biswas, M., Bryant, C., Templeton, K., Al-Wahb, M., et al. (2007). Transcriptome analysis reveals season-specific rbcS gene expression profiles in diploid perennial ryegrass (Lolium perenne L.). Plant Biotechnol. J. 5, 146-161. doi: 10.1111/j.1467-7652.2006.00228.x

Scharf, K.-D., Berberich, T., Ebersberger, I., and Nover, L. (2012). The plant heat stress transcription factor (Hsf) family: structure, function and evolution. Biochim. Biophys. Acta Gene Regul. Mech. 1819, 104-119. doi: 10.1016/j.bbagrm. 2011.10.002

Schramm, F., Ganguli, A., Kiehlmann, E., Englich, G., Walch, D., and Von Koskull-Doring, P. (2006). The heat stress transcription factor HsfA2 serves as a regulatory amplifier of a subset of genes in the heat stress response in Arabidopsis. Plant Mol. Biol. 60, 759-772. doi: 10.1007/s11103-0055750- $\mathrm{x}$

Schulze, E.-D., Beck, E., and Muller-Hohenstein, K. (2005). Plant Ecology. Berlin: Springer.

Senthil-Kumar, M., Kumar, G., Srikanthbabu, V., and Udayakumar, M. (2007). Assessment of variability in acquired thermotolerance: potential option to study genotypic response and the relevance of stress genes. J. Plant Physiol. 164, 111-125. doi: 10.1016/j.jplph.2006.09.009

Skogqvist, N. G. R. (1974). Induced heat sensitivity of wheat roots and protecting effect of ethanol and kinetin. Physiol. Plant. 32, 166-169. doi: 10.1111/j.13993054.1974.tb03746.x

Song, J., Liu, Q., Hu, B., and Wu, W. (2016). Comparative transcriptome profiling of Arabidopsis Col-0 in responses to heat stress under different light conditions. Plant Growth Regul. 79, 209-218. doi: 10.1007/s10725-015-0126-y

Song, Y., Chen, Q., Ci, D., Shao, X., and Zhang, D. (2014). Effects of high temperature on photosynthesis and related gene expression in poplar. BMC Plant Biol. 14:111. doi: 10.1186/1471-2229-14-111

Staneloni, R. J., Jose Rodriguez-Batiller, M., and Casal, J. J. (2008). Abscisic acid, high-light, and oxidative stress down-regulate a photosynthetic gene via a promoter motif not involved in phytochrome-mediated transcriptional regulation. Mol. Plant 1, 75-83. doi: 10.1093/mp/ssm007

Stroch, M., Spunda, V., and Kurasova, I. (2004). Non-radiative dissipation of absorbed excitation energy within photosynthetic apparatus of higher plants. Photosynthetica 42, 323-337. doi: 10.1023/B:PHOT.0000046149. 97220.18

Studer, B., Byrne, S., Nielsen, R. O., Panitz, F., Bendixen, C., Islam, M. S., et al. (2012). A transcriptome map of perennial ryegrass (Lolium perenne L.). BMC Genomics 13:140. doi: 10.1186/1471-2164-13-140

Sugita, S. (1991). Breeding of new cultivars of perennial ryegrass in Japan. Japn. Agric. Res. Q. 25, 195-201.

Sun, W., Van Montagu, M., and Verbruggen, N. (2002). Small heat shock proteins and stress tolerance in plants. Biochim. Biophys. Acta 1577, 1-9. doi: 10.1016/ S0167-4781(02)00417-7

Suzuki, N., Miller, G., Sejima, H., Harper, J., and Mittler, R. (2013). Enhanced seed production under prolonged heat stress conditions in Arabidopsis thaliana plants deficient in cytosolic ascorbate peroxidase 2. J. Exp. Bot. 64, 253-263. doi: 10.1093/jxb/ers335

Tang, R., Zhu, W., Song, X., Lin, X., Cai, J., Wang, M., et al. (2016). Genomewide identification and function analyses of heat shock transcription factors in potato. Front. Plant Sci. 7:490. doi: 10.3389/fpls.2016.00490

Taylor, L., Nunes-Nesi, A., Parsley, K., Leiss, A., Leach, G., Coates, S., et al. (2010). Cytosolic pyruvate,orthophosphate dikinase functions in nitrogen remobilization during leaf senescence and limits individual seed growth and nitrogen content. Plant J. 62, 641-652. doi: 10.1111/j.1365-313X.2010. 04179.x

Thum, K. E., Kim, M., Christopher, D. A., and Mullet, J. E. (2001). Cryptochrome 1 , cryptochrome 2, and phytochrome A co-activate the chloroplast psbD blue light-responsive promoter. Plant Cell 13, 2747-2760. doi: 10.1105/tpc.13.12. 2747

Torres, M. A., and Dangl, J. L. (2005). Functions of the respiratory burst oxidase in biotic interactions, abiotic stress and development. Curr. Opin. Plant Biol. 8, 397-403. doi: 10.1016/j.pbi.2005.05.014 
Trevanion, S. J., Brooks, A. L., and Leegood, R. C. (1995). Control of gluconeogenesis by phosphoenolpyruvate carboxykinase in cotyledons of Cucurbita pepo L. Planta 196, 653-658. doi: 10.1007/BF01106757

Tronconi, M. A., Fahnenstich, H., Weehler, M. C. G., Andreo, C. S., Fluegge, U.-I., Drincovich, M. F., et al. (2008). Arabidopsis NAD-malic enzyme functions as a homodimer and heterodimer and has a major impact on nocturnal metabolism. Plant Physiol. 146, 1540-1552. doi: 10.1104/pp.107.114975

Turgeon, A. J. (ed.) (2011). Turfgrass Management. Upper Saddle River, NJ: Prentice-Hall.

Wahid, A., Gelani, S., Ashraf, M., and Foolad, M. (2007). Heat tolerance in plants: an overview. Environ. Exp. Bot. 61, 199-223. doi: 10.1016/j.envexpbot.2007. 05.011

Wan, X., Zhou, Q., Wang, Y., Wang, W., Bao, M., and Zhang, J. (2015). Identification of heat-responsive genes in carnation (Dianthus caryophyllus L.) by RNA-seq. Front. Plant Sci. 6:519. doi: 10.3389/fpls.2015.00519

Wang, D. F., and Luthe, D. S. (2003). Heat sensitivity in a bentgrass variant. Failure to accumulate a chloroplast heat shock protein isoform implicated in heat tolerance. Plant Physiol. 133, 319-327. doi: 10.1104/pp.102.018309

Wang, K., Zhang, X., and Ervin, E. (2012). Antioxidative responses in roots and shoots of creeping bentgrass under high temperature: effects of nitrogen and cytokinin. J. Plant Physiol. 169, 492-500. doi: 10.1016/j.jplph.2011.12.007

Wang, K., Zhang, X., and Ervin, E. (2013). Effects of nitrate and cytokinin on creeping bentgrass under supraoptimal temperatures. J. Plant Nutr. 36, 1549-1564. doi: 10.1080/01904167.2013.799184

Wang, K., Zhang, X., and Ervin, E. H. (2016). "Small heat shock proteins, a key player in grass plant thermotolerance," in Heat Shock Proteins and Plants, eds A. A. A. Asea, P. Kaur, and S. K. Calderwood (Cham: Springer International Publishing), 41-64.

Wang, R., and Xiong, X. (2016). Effect of temperature stress on growth and metabolism in perennial ryegrass. Acta Pratacult. Sin. 25, 81-90. doi: 10.1093/ jxb/err161

Wang, Y., Dai, Y., Tao, X., Wang, J. Z., Cheng, H. Y., Yang, H., et al. (2016). Heat shock factor genes of tall fescue and perennial ryegrass in response to temperature stress by RNA-Seq analysis. Front. Plant Sci. 6:1226. doi: 10.3389/ fpls.2015.01226

Wang, Z., Gerstein, M., and Snyder, M. (2009). RNA-Seq: a revolutionary tool for transcriptomics. Nat. Rev. Genet. 10, 57-63. doi: 10.1038/nrg2484

Wang, Z.-M., Li, H.-X., Liu, X.-F., He, Y., and Zeng, H.-L. (2015). Reduction of pyruvate orthophosphate dikinase activity is associated with high temperatureinduced chalkiness in rice grains. Plant Physiol. Biochem. 89, 76-84. doi: 10.1016/j.plaphy.2015.02.011

Waters, E. R., Lee, G. J., and Vierling, E. (1996). Evolution, structure and function of the small heat shock proteins in plants. J. Exp. Bot. 47, 325-338. doi: 10.1093/ jxb/47.3.325

Wigley, T. M. L., and Raper, S. C. B. (1992). Implications for climate and sea level of revised IPCC emissions scenarios. Nature 357, 293-300. doi: 10.1038/357293a0

Wu, L., Taohua, Z., Gui, W., Xu, L., Li, J., and Ding, Y. (2015). Five pectinase gene expressions highly responding to heat stress in rice floral organs revealed by
RNA-seq analysis. Biochem. Biophys. Res. Commun. 463, 407-413. doi: 10.1016/ j.bbrc.2015.05.085

Wullschleger, S., Loewith, R., and Hall, M. N. (2006). TOR signaling in growth and metabolism. Cell 124, 471-484. doi: 10.1016/j.cell.2006.01.016

Xiong, Y., Mccormack, M., Li, L., Hall, Q., Xiang, C., and Sheen, J. (2013). GlucoseTOR signalling reprograms the transcriptome and activates meristems. Nature 496, 181-186. doi: 10.1038/nature 12030

Xu, Q. Z., and Huang, B. R. (2000). Growth and physiological responses of creeping bentgrass to changes in air and soil temperatures. Crop Sci. 40, 1363-1368. doi: $10.2135 /$ cropsci2000.4051363x

Xu, Y., and Huang, B. R. (2007). Heat-induced leaf senescence and hormonal changes for thermal bentgrass and turf-type bentgrass species differing in heat tolerance. J. Am. Soc. Hortic. Sci. 132, 185-192.

Xu, Y., Tian, J., Gianfagna, T., and Huang, B. R. (2009). Effects of SAG12ipt expression on cytokinin production, growth and senescence of creeping bentgrass (Agrostis stolonifera L.) under heat stress. Plant Growth Regul. 57, 281-291. doi: 10.1007/s10725-008-9346-8

Xu, Y.-H., Liu, R., Yan, L., Liu, Z.-Q., Jiang, S.-C., Shen, Y.-Y., et al. (2012). Lightharvesting chlorophyll a/b-binding proteins are required for stomatal response to abscisic acid in Arabidopsis. J. Exp. Bot. 63, 1095-1106. doi: 10.1093/jxb/ err315

Xue, G.-P., Sadat, S., Drenth, J., and Mcintyre, C. L. (2014). The heat shock factor family from Triticum aestivum in response to heat and other major abiotic stresses and their role in regulation of heat shock protein genes. J. Exp. Bot. 65, 539-557. doi: 10.1093/jxb/ert399

Young, M. D., Wakefield, M. J., Smyth, G. K., and Oshlack, A. (2010). Gene ontology analysis for RNA-seq: accounting for selection bias. Genome Biol. 11:R14. doi: 10.1186/gb-2010-11-2-r14

Zhang, J., Wang, Y., Yang, H., and Li, L. (2013). "The improvement of thermotolerance in tall fescue and perennial ryegrass by activating the antioxidative system," in Progress in Environmental Science and Engineering, Pts 1-4, eds Q. J. Xu, Y. H. Ju, and H. H. Ge (Zurich: Trans Tech Publications Inc), 249-253.

Zhou, W., and Leul, M. (1999). Uniconazole-induced tolerance of rape plants to heat stress in relation to changes in hormonal levels, enzyme activities and lipid peroxidation. Plant Growth Regul. 27, 99-104. doi: 10.1023/A:1006165603300

Conflict of Interest Statement: The authors declare that the research was conducted in the absence of any commercial or financial relationships that could be construed as a potential conflict of interest.

Copyright (c) 2017 Wang, Liu, Tian, Huang, Shi, Dai and Zhang. This is an openaccess article distributed under the terms of the Creative Commons Attribution License (CC BY). The use, distribution or reproduction in other forums is permitted, provided the original author(s) or licensor are credited and that the original publication in this journal is cited, in accordance with accepted academic practice. No use, distribution or reproduction is permitted which does not comply with these terms. 